\title{
Moment Tensor Inversions of Icequakes on Gornergletscher, Switzerland
}

\author{
by Fabian Walter, John F. Clinton, Nicholas Deichmann, Douglas S. Dreger, \\ Sarah E. Minson, and Martin Funk
}

\begin{abstract}
We have determined seismic source mechanisms for shallow and intermediate-depth icequake clusters recorded on the glacier Gornergletscher, Switzerland, during the summers of 2004 and 2006. The selected seismic events are part of a large data set of over 80,000 seismic events acquired with a dense seismic network deployed in order to study the yearly rapid drainage of Gornersee lake, a nearby icemarginal lake. Using simple frequency and distance scaling and Green's functions for a homogeneous half-space, we calculated moment tensor solutions for icequakes with $M_{\mathrm{w}}-1.5$ using a full-waveform inversion method usually applied to moderate seismic events $\left(M_{\mathrm{w}}>4\right)$ recorded at local to regional distances $(\approx 50-700 \mathrm{~km})$. Inversions from typical shallow events are shown to represent tensile crack openings. This explains well the dominating Rayleigh waves and compressive first motions observed at all recording seismograms. As these characteristics can be observed in most icequake signals, we believe that the vast majority of icequakes recorded in the $2 \mathrm{yr}$ is due to tensile faulting, most likely caused by surface crevasse openings. We also identified a shallow cluster with somewhat atypical waveforms in that they show less dominant Rayleigh waves and quadrantal radiation patterns of first motions. Their moment tensors are dominated by a large double-couple component, which is strong evidence for shear faulting. Although less than a dozen such icequakes have been identified, this is a substantial result as it shows that shear faulting in glacier ice is generally possible even in the absence of extreme flow changes such as during glacier surges. A third source of icequakes was located at $100 \mathrm{~m}$ depth. These sources can be represented by tensile crack openings. Because of the high-hydrostatic pressure within the ice at these depths, these events are most likely related to the presence of water lenses that reduce the effective stress to allow for tensile faulting.
\end{abstract}

Online Material: Background information and results of moment tensor inversions.

\section{Introduction}

Despite recent progress in numerical modeling in glaciology, the effect of brittle deformation on glacier dynamics has received relatively little attention. Yet surface crevassing, glacier calving, breaking-off of hanging glaciers, and basal stick-slip motion indicate that fracture processes play a substantial role in glacier motion. Seismic techniques can be of pivotal importance in the studies of these phenomena as the elastic waves emitted by fracturing can be measured at a distance from the source. The sites of interest range from small alpine glaciers to the Antarctic and Greenland ice sheets, including their largest outlet glaciers. In every case, accurate timing, locations, and waveforms of glacier-related seismic events allow for valuable insights into the physical processes that govern glacier flow.

Glacial earthquakes are seismic signals associated with large glaciers in Alaska, Antarctica, and Greenland (Ekström et al., 2003). Although they are strong enough to be detected on global seismic networks, they have only recently been identified. Their seismograms lack the high-frequency initial arrivals traditional event detection techniques are based upon. The long-period surface waves generated by these glacial events can, on the other hand, be modeled by single forces representing a slip motion in a direction consistent with the flow of glaciers near or at epicentral locations. Recently, Joughin et al. (2008) published sound evidence that glacial earthquakes are related to major calving events. The actual mechanism that produces the single forces needed to model the surface waves has not been identified. Glacier-slip motion in response to the force imbalance following a calving event or rotational motion of a calving iceberg are two possible candidates (Tsai et al., 2008). Detailed analyses of temporal variations of glacial earthquakes in Greenland fur- 
thermore suggest a relationship with surface melt, ice dynamics, and changing global climate (Ekström et al., 2006; Tsai and Ekström, 2007). Wiens et al. (2008) have recently reported stick-slip motion of the Whillans ice stream in West Antarctica recorded with simultaneous Global Positioning System and seismic instruments. The latter were located up to $1000 \mathrm{~km}$ away from the West Antarctic ice sheet. Unlike the Ekström events, at least some parts of the seismic waveforms could be modeled with a double-couple source. This raises the questions, if a new type of glacial earthquake has been discovered and if there are systematic differences between the seismic activity emitted by the Greenland and Antarctic ice sheets.

A much weaker type of seismic activity associated with glacier-slip motion originates at the base of Antarctic ice streams and has been investigated for several decades. These events can only be studied locally because they are too weak to be detected by global or even regional seismic networks. From the frequency content of the seismograms it can be deduced that the slip during these events does not significantly contribute to the motion of the ice stream (Anandakrishnan and Bentley, 1993; Danesi et al., 2007). Smith (2006) showed that spatial variations in basal seismic activity can be linked to variations in subglacial conditions such as deforming and lodged underlying sediments. Seismic signal characteristics and spatial and temporal variations in seismic activity also played an important role in studies that aimed at explaining the recent stagnation of Ice Stream C at the Siple Coast of the West Antarctic ice sheet (Anandakrishnan and Bentley, 1993; Anandakrishnan and Alley, 1994; Anandakrishnan and Alley, 1997a,b).

Recently, O'Neel et al. (2006) and O'Neel and Pfeffer (2007) studied seismic signals radiated from calving events at Columbia Glacier, Alaska. The frequency content of these icequakes allows for detection and thus monitoring of the calving activity via seismic measurements. Furthermore, frequency contents of the recorded signals led the authors to argue for a fluid-filled crack source model as the mechanism weakening the ice and eventually leading to calving.

Icequakes in alpine glaciers have been investigated in a variety of contexts. Several types of source mechanisms have been postulated or assumed, such as surface crevasse formation (e.g., Neave and Savage, 1970; Deichmann et al., 2000), stick-slip motion (Weaver and Malone, 1979; Roux et al., 2008), resonant water-filled cavities (Métaxian et al., 2003), or bottom crevasse formation due to increased basal drag during low subglacial water pressures (Walter et al., 2008). Whereas these conclusions were drawn on the basis of hypocentral locations, temporal variations in activity, or frequency content of the seismograms, we are unaware of any publication on full-waveform inversions for the source parameters for these classes of events. Information about source types, source geometry, and volumetric changes open new possibilities to study glacier dynamics and hydrology via seismic techniques. The specific questions to be answered are: What kind of fracture modes are possible in ice? Are all icequakes a result of tensile fracturing, or can they also be due to shear faulting? Furthermore, the source mechanisms of icequakes at greater depths may also shed some light on the influence that water has on fracturing (hydrofracturing). The presence of pressurized water can generally reduce the effective stress and thus drive tensile cracks into basal ice layers (Van der Veen, 1998). Similarly, englacial water flow may open up or enlarge cavities within the ice.

In this manuscript we present a method for moment tensor inversions using full waveforms of icequakes that were recorded on Gornergletscher, Switzerland, during the summers of 2004 and 2006. The data used for the present analysis were acquired as part of an investigation of the yearly subglacial drainages of Gornersee, a nearby ice-marginal lake (e.g., Huss et al., 2007; Sugiyama et al., 2007; Walter et al., 2008). The instrumentation for the 2004 and 2006 seismic arrays consisted of 14 and 24 seismometers, respectively, most of which were installed at the glacier surface (Fig. 1). Each array also contained one or more seismometers at depths between 50 and $250 \mathrm{~m}$ to better constrain hypocenter locations. The high-pass corner frequencies of the sensors were between 1 and $28 \mathrm{~Hz}$, and the instruments were operated at high-sampling frequencies $(1000-4000 \mathrm{~Hz})$ in trigger mode. For a detailed description of the instrumentation and seismic data as well as detection and location algorithms, the reader is referred to Walter et al. (2008).

The moment tensor is a concise representation of the seismic source in terms of force couple equivalents, and its determination is a standard practice in earthquake seismology (e.g. Jost and Hermann, 1989; Aki and Richards, 2002). Whereas tectonic earthquakes are expected to have pure double-couple sources, typical icequakes can be expected to be related to tensile failure. Their sources can thus be expected to have significant isotropic and compensated linear vector dipole (CLVD) components (E) see Background Information on Moment Tensor Inversions in the electronic edition of $B S S A$ ). Thus deviatoric-moment tensors inversion routines used to describe typical earthquakes are not adequate for icequake sources. Using the general method developed by Dreger (2003), we follow Minson and Dreger (2008) to calculate full-moment tensors as well as investigate the applicability of constrained moment tensors that constitute physical models of specific sources such as tensile crack openings and shear faults. We will focus the analysis on seismic events that originate from near the glacier surface as well as from intermediate depths, a considerable distance from the surface crevassing zone and from the glacier bed.

\section{Icequake Waveform Discrimination and Locations}

Over 35,000 and 50,000 icequakes were recorded during the field seasons of 2004 and 2006, respectively. In agreement with seismicity observed in previous studies on alpine glaciers (Neave and Savage, 1970; Deichmann et al., 2000), we associate the vast majority (over 99\%) of these signals with crevasses opening near the surface. For an alpine 
(a)

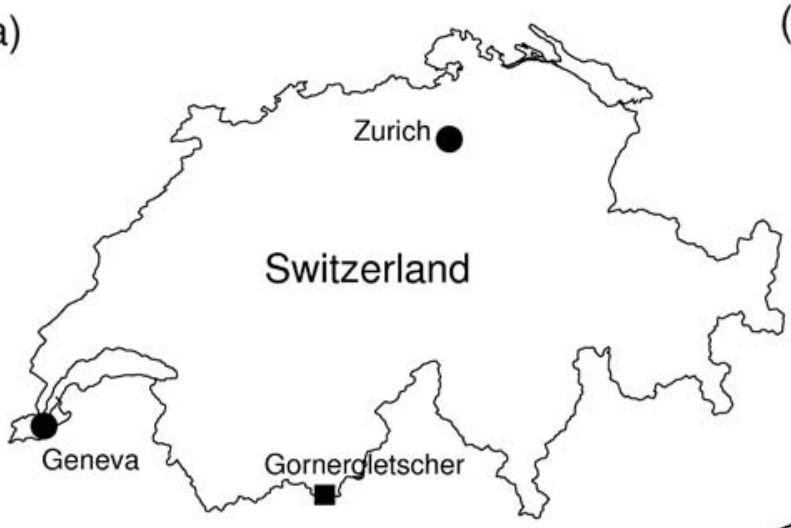

(c)

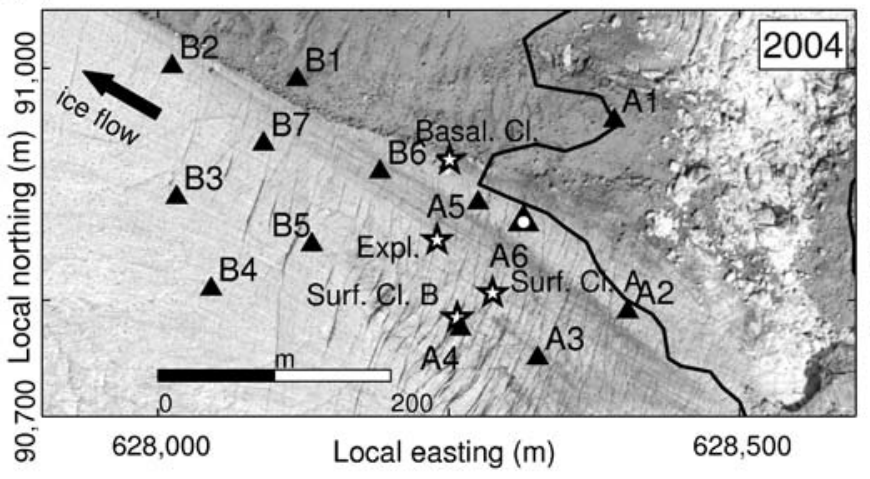

(b)

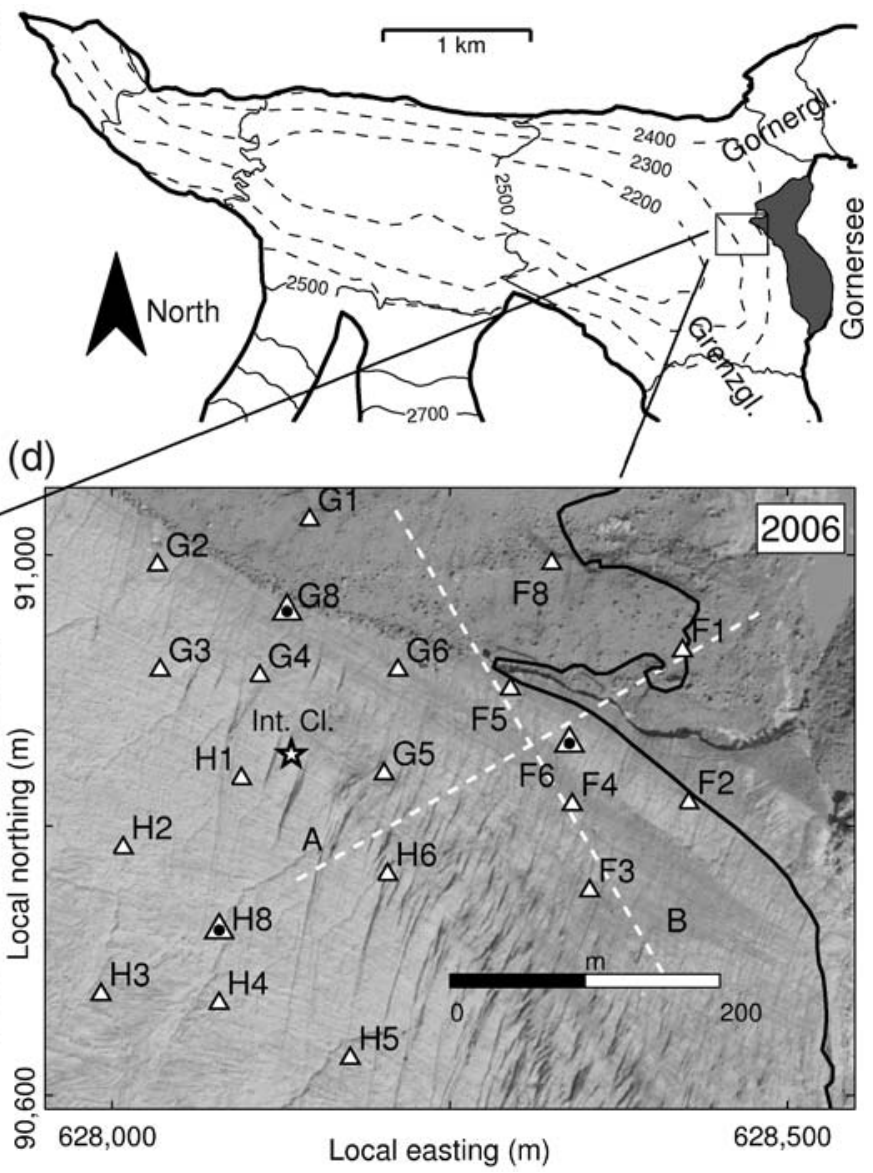

Figure 1. (a) Location of Gornergletscher and (b) map of tongue of Gornergletscher. The latter also shows Gornersee, the locations of the seismic networks (box near the lake) and contour lines (in meters above sea level) that approximate the glacier's surface (solid curves) and bed (dashed curves). Ortho-photographs with seismic networks from (c) 2004 and (d) 2006. Seismometers are indicated by triangles and epicenters of event clusters studied in this work by stars (surface cluster A, surface cluster B, as well as basal and intermediate clusters and explosions). The triangles with dots indicate sites where a surface and a deep borehole seismometer were installed. The solid line represents the outlines of Gornersee at the maximum water level reached in the corresponding year. Coordinates are given in the Swiss Grid. Upper portions of both ortho-photographs are darker reflecting moraine debris on the glacier surface. (d) The cross sections shown in Figure 3 are indicated by the white dashed lines.

glacier, surface crevassing is confined to the top $20 \mathrm{~m}$ of the glacier ice (Paterson, 1994). Water-filled fractures, which can potentially penetrate the glacier to larger depths, have not been observed at the study site. As the main goal of the seismic investigation on Gornergletscher was to investigate brittle fracture of glacier ice due to englacial and subglacial water flow, events that occur well below this depth are of particular interest. An automated waveform discriminator and cross-correlation search were used to efficiently identify about 1000 events each year whose waveforms are substantially different from those of the typical surface crevasse events (Walter et al., 2008). The arrival times of these events were picked by hand. The hypocenters were determined via an inversion algorithm identifying a location in space that minimizes the differences between calculated and handpicked arrival times (Lee and Steward, 1981). Overall, only a very small portion of icequakes (without reliable statistics, we estimate significantly less than $1 \%$ of the complete data set) has been located at depths well below the reach of surface crevasses.

In the remainder of this article we discuss specific groups of icequakes recorded on Gornergletscher. We present source mechanisms of typical examples of shallow as well as deep icequakes. In addition, we analyzed a group of shallow icequakes with double-couple sources and fundamentally different signal characteristics from a typical shallow event associated with crevasse opening. Even though interesting, we have found only very few such exceptional icequakes, and their number may be statistically insignificant in comparison to the large number of crevasse opening events. Yet their occurrence raises some fundamental questions concerning the nature of brittle deformation of ice.

\section{Characteristics of Near-Surface Events}

Icequakes from a number of surface crevasse fields were recorded in both summers. The seismic arrays had an aper- 
ture of $\approx 200 \mathrm{~m}$ and were placed near a rather active surface crevassing zone (Fig. 1), and thus a large number of near-surface events were recorded with a good azimuthal coverage.

The waveform of a typical near-surface event is shown in Figure 2a. This event is part of a cluster of 5 events (henceforth surface cluster A), which occurred between 21 June and 22 June 2004 near station A4 (epicentral location shown in Fig. 1). The relatively short period of activity ( $24 \mathrm{hr}$ ) of this cluster likely reflects a crevasse opening leading to stress relaxation. All events occurred within meters of the glacier surface (Fig. 3). As is typical for most icequakes, the signals of this cluster are characterized by compressive first motion at

(a) Surface cluster A event (2004)

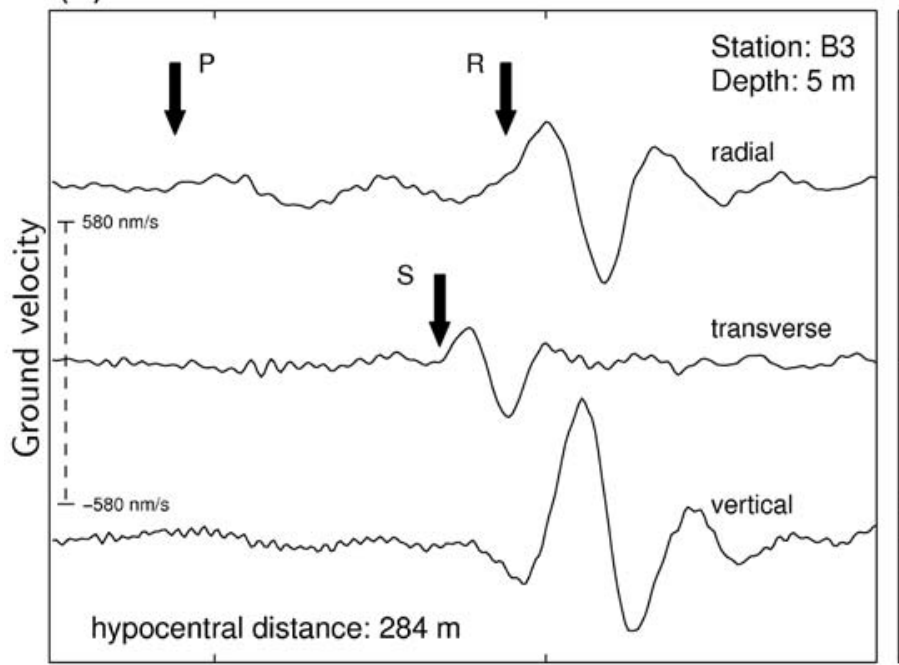

(c)

Intermediate cluster event (2006)

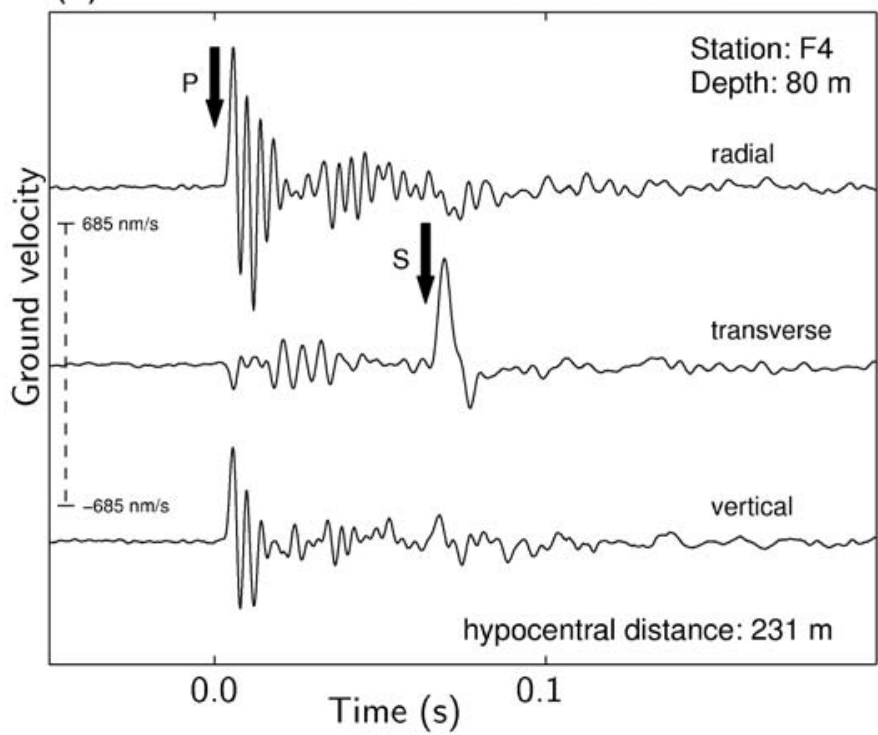

all azimuths. This is evidence for a significant isotropic moment tensor component. A further typical characteristic is the dominant Rayleigh wave at more distant stations such as B3, for which the waveform is shown in Figure 2a.

Figure $2 b$ shows a waveform of a surface event that belongs to another cluster inside the crevassing zone (henceforth surface cluster B). This cluster also consists of 5 events, and it was active for only a few hours on 5 July 2004 (see Fig. 1 for epicentral location). The waveforms show substantial differences to those of surface cluster A. For equal source-receiver distances and azimuths, the Rayleigh wave of the surface cluster B events is less developed than that of the surface cluster A events. Specifically, at station B3 the

\section{(b) Surface cluster B event (2004)}

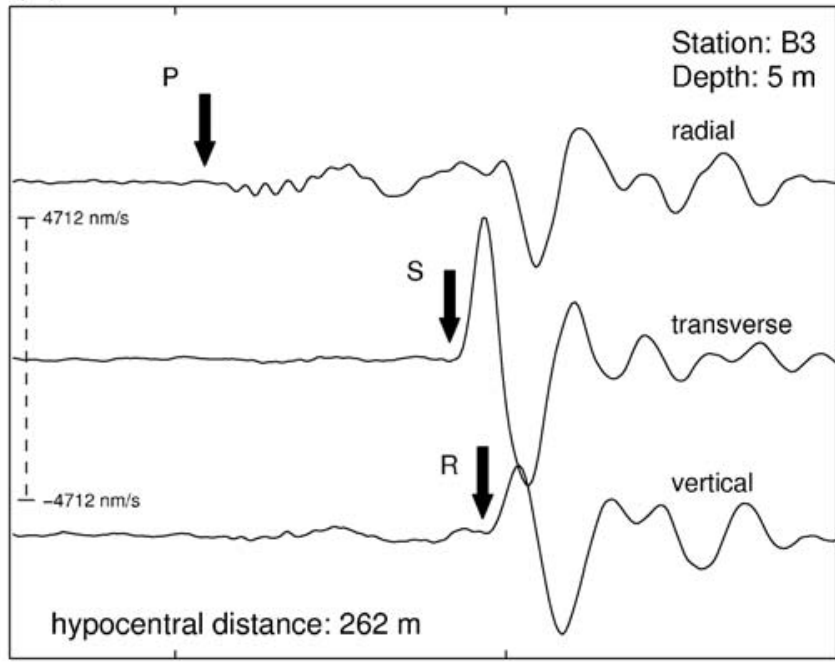

(d)

Basal cluster event (2004)

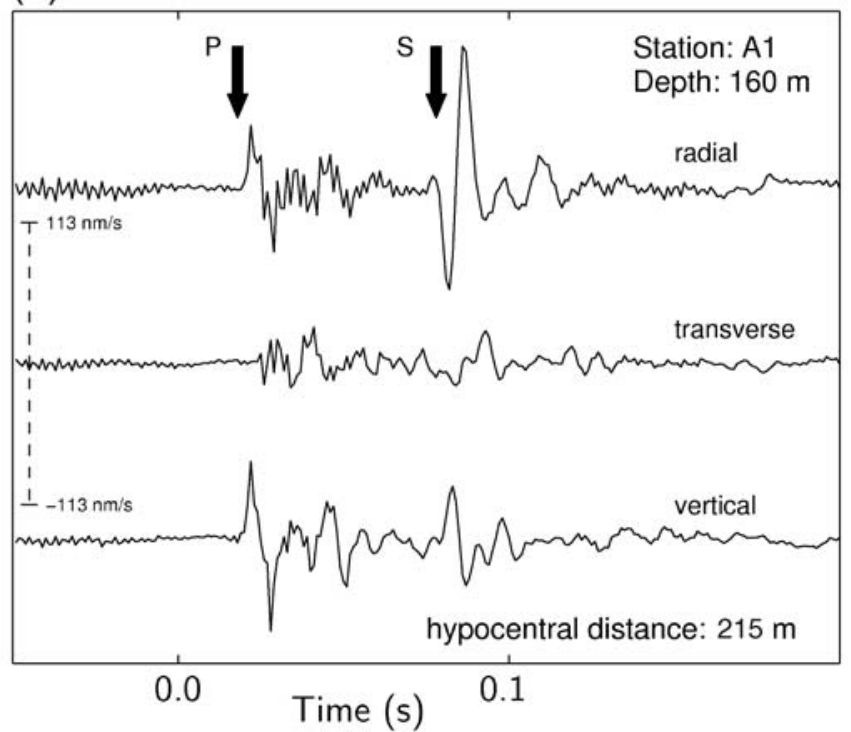

Figure 2. Velocity seismograms of four types of icequakes recorded by surface seismometers. (a) and (b) the seismograms of the two shallow events were recorded at the same station (B3). Because the sources occurred close to each other, the different relative strengths of the $S$ and Rayleigh phases are likely due to source effects rather than path effects. The seismograms of the (c) intermediate and (d) basal events show higher frequencies and are dominated by impulsive $P$ and $S$ waves. They do not have a notable Rayleigh phase. The $P$ waves of the shallow events, on the other hand, are hardly visible. Theoretical $P_{-}, S-$, and Rayleigh-arrival times are indicated by arrows. 

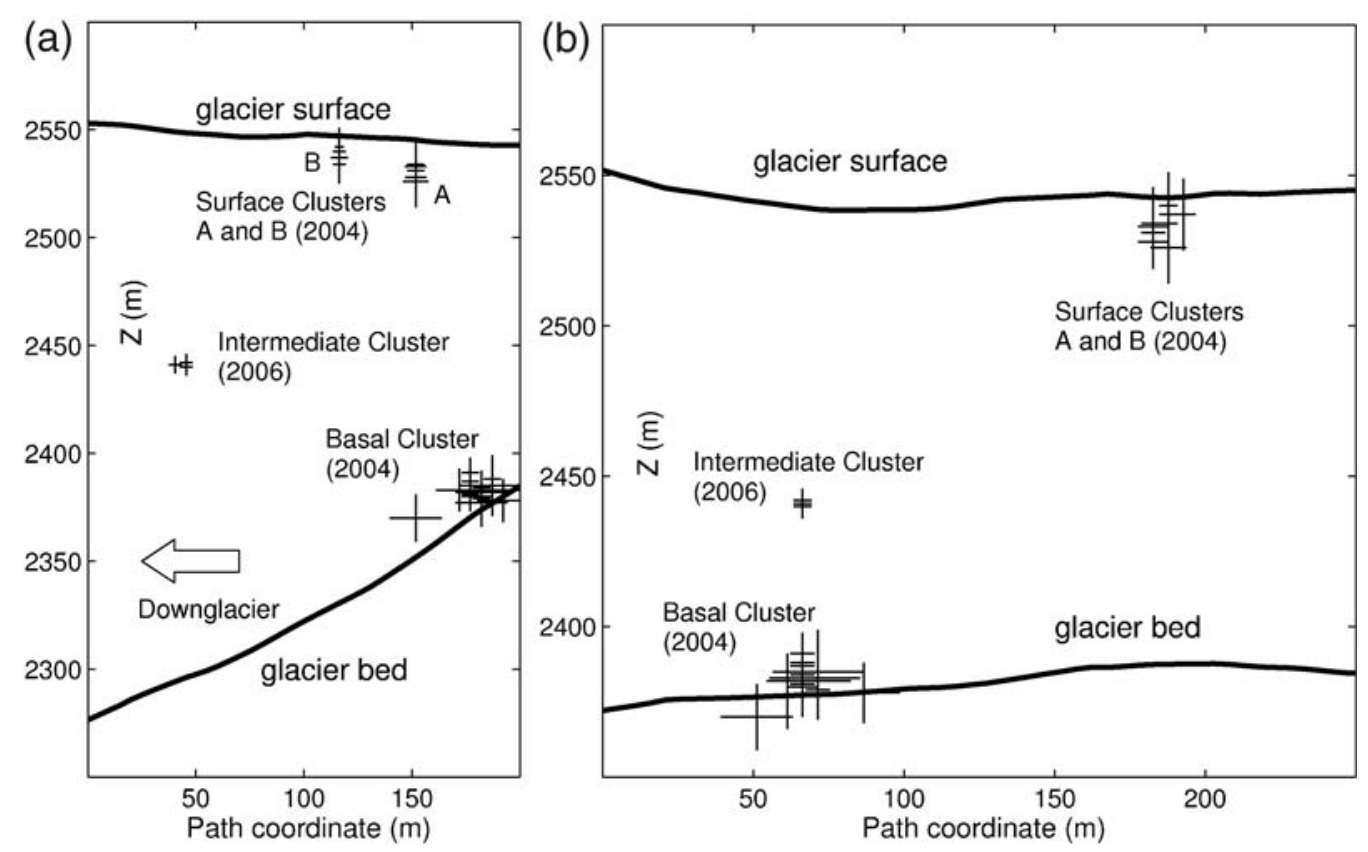

Figure 3. Hypocentral locations of the icequakes presented in this article. The plots are taken along two cross sections (Fig. 1d). (a) Cross section along the steepest gradient of the glacier bed, corresponding roughly to the direction of glacier flow, and (b) cross section perpendicular to this steepest topography (see Fig. 1 for bed topography). The sizes of hypocentral markings indicate location uncertainties in horizontal and vertical directions.

$S$ wave is stronger than the Rayleigh wave, whereas for the surface cluster A events it is the other way around (compare panels $a$ and $b$ of Fig. 2). These differences are most likely caused by source effects rather than path effects because the epicenters of both surface clusters lie within $40 \mathrm{~m}$ of each other and their depths are also comparable (Fig. 3). The first arrivals of surface cluster B events suggest a quadrantal distribution of compressive and dilatational motion (Fig. 4), which is typical for double-couple sources. This characteristic has only been noted in about a dozen icequakes. The

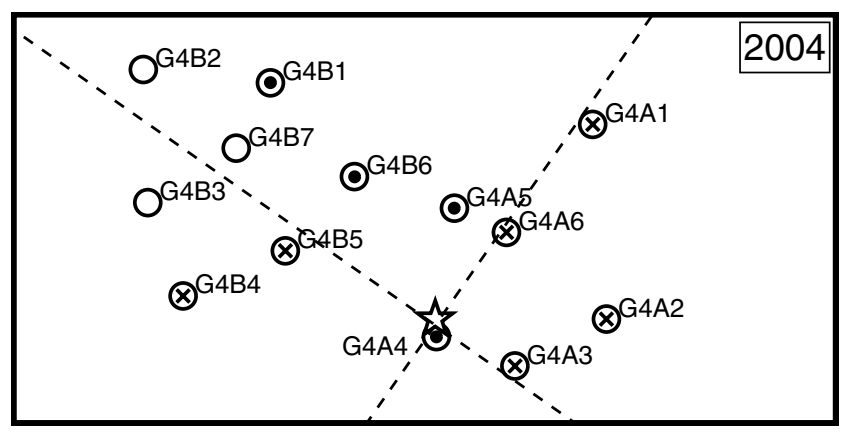

Figure 4. Distribution of compressive and dilatational arrivals around a surface cluster B event recorded on the 2004 seismic network (Fig. 1). The event epicenter is indicated by the star. Dots and crosses mark seismometers with upward compressive and downward dilatational first motions, respectively. Empty circles are stations at which the first arrivals were not impulsive enough to determine their polarity. The observed polarities suggest a quadrantal radiation pattern consistent with a double-couple source. The dashed lines separate the quadrants. usual case is compressive first motion at all azimuths like the events of surface cluster A.

\section{Characteristics of Deep Icequakes}

About 80 and 200 icequakes were located at depths well below the surface crevassing zone in 2004 and 2006, respectively. In 2004, all of these events were located near the glacier bed, whereas in 2006 about 20 were located at intermediate depths. Most basal icequakes cluster in distinct regions. A waveform from an event belonging to a basal cluster is given in Figure 2d. This cluster lies at a depth of $160 \mathrm{~m}$, in the immediate vicinity of the glacier bed (epicentral location shown in Fig. 1) and consists of 29 events that occurred over a period of more than two weeks. The waveform shown has a higher frequency content compared to the signals of nearsurface events. The lower frequency content of the latter is explained by the high density of vertical crevasses in the shallow ice layers, which tend to filter out high frequencies for waves from shallow events, which must cross the crevasses. Typical features of deep icequakes are the impulsive $P$ wave and the lack of a notable Rayleigh wave.

Three events located at $100 \mathrm{~m}$ depth constitute another event type investigated in this study (Fig. 2c). They form a cluster (henceforth intermediate cluster), which was active for a few hours on 16 June 2006 (see Fig. 1 for epicentral location). At this depth, they are occurring significantly below the surface crevassing zone, and they cannot be associated with fracture near the glacier bed. For modeling purposes, reflection effects from the surface and the glacier bed 
can thus be neglected at this depth. Like the basal events, the signals of the intermediate events contain more energy at high frequencies than surface events and also show impulsive $P$ waves. $S$ phases of the intermediate icequakes are strongest on the transverse components whereas for basal cluster events the $S$ energy is dominant on the radial component. This does not seem to be an effect of different source-receiver azimuths and is thus due to different source mechanisms or reflections off the glacier bed in the case of the basal events.

In the present study we focus on source modeling of near-surface and intermediate events. Whereas we present some basal events for the sake of completeness, we do not show any waveform modeling results of their signals. For sources near the glacier base, the 2D or even 3D topography of the glacier bed produces complicated reflections that cannot be accurately modeled using a 1D velocity profile. Synthetic seismograms show that these sources are close enough to the ice-bedrock interface that the reflections interfere with the direct waves. Thus, the amplitudes of the first arrivals are substantially altered. If Green's functions are calculated for an incorrect velocity model, these changes in amplitude may be mapped into source properties rather than path properties. For the intermediate and near-surface events this effect is less severe as the reflections are weaker and are part of the coda and not part of the direct waves.

Furthermore, the waves of intermediate events traverse only few surface crevasses on their way to the surface seismometers, compared to the waves of near-surface events. For these reasons source modeling of intermediate events is found to be particularly straight forward.

\section{Moment Tensor Inversions}

\section{Numerical Tools}

Besides calculating the full-moment tensor we also applied two constrained inversion schemes. In the first one the moment tensor is deviatoric and in the second one it is a superposition of a tensile crack and a double couple (henceforth crack + DC, Minson et al., 2007). The tensile crack moment tensor can be decomposed into an isotropic part and a CLVD. For a Poisson's ratio of 0.36 , as used in the present study, the isotropic component is almost five times bigger than the CLVD ( $($ ) see Background Information on Moment Tensor Inversions in the electronic edition of BSSA).

In our approach, we use 1D Green's functions representing a homogeneous half-space with $P$ and $S$ velocities of $3.63 \mathrm{~km} / \mathrm{sec}$ and $1.76 \mathrm{~km} / \mathrm{sec}$, respectively. The corresponding seismic attenuation quality factors are 600 and 300 , respectively. As discussed in the following section, this is a good approximation to the velocity model of the glacier. The Green's functions were computed using the FKRPROG software developed by Chandan Saikia of URS (Saikia, 1994). The deviatoric- and full-moment tensor solutions were calculated by applying a corrected form (Minson et al.,
2007) of the linear time domain moment tensor inversion scheme used by Dreger et al. (2000) and Dreger and Woods (2002). Moment tensors of the crack + DC model were determined with a grid search algorithm developed and applied by Minson et al. (2007). Whereas the full-inversion scheme has 6 degrees of freedom corresponding to the independent elements of the moment tensor, the deviatoric- and crack + DC-inversion schemes only have 5 degrees of freedom. As a measure of fit quality, the variance reduction, $V R$, given by

$$
V R=\left(1.0-\frac{\int(\text { data }- \text { synthetic })^{2} d t}{\int(\text { data })^{2} d t}\right) \times 100 \%,
$$

was calculated for each fit. A perfect fit gives a variance reduction of 100\%. Following Templeton and Dreger (2006), the variance reduction is also used to perform F-test statistics (Menke, 1989). This is necessary as the fit quality is expected to increase with the complexity of the model. Specifically, we evaluate if differences in variance reduction calculated with the different inversion schemes reflect physical source properties or if they are consequences of the different numbers of degrees of freedom included in the source model. The time offset used to align data and synthetics to maximize the variance reduction is called the zcor value. In all cases the zcor value is adjusted manually through trial and error to increase the variance reduction of the waveform fit. It should be mentioned that although the same Green's functions and the same zcor values are used in the three different inversions for a given event, the variance reduction of the crack + DC-grid search sometimes exceeds the variance reduction of the full-moment tensor inversion. This is not expected, as a full-moment tensor contains more degrees of freedom than a crack + DC-moment tensor (6 and 5, respectively). The crack + DC-grid search can find fits with higher variance reductions because it maximizes the variance reduction itself. The full- and deviatoric-moment tensor inversions, on the other hand, determine a least-squares solution. Both techniques minimize a measure of misfit, but the respective maxima and minima do not necessarily coincide. Using F-test statistics we found that whenever crack + DC inversion calculates a slightly higher variance reduction than the full-moment tensor scheme, it is not statistically significant.

\section{Moment Tensor Inversion for Icequakes}

The moment tensor related numerical tools described in the previous section typically are used to model signals from moderate seismic events $\left(M_{\mathrm{w}}>4\right)$ recorded at regional distances $(\approx 50-700 \mathrm{~km})$. Relevant periods of these signals are between 10 and $100 \mathrm{sec}$. The Green's functions are generated for 1D velocity models appropriate for these dimensions and frequencies. In order to apply these available software packages to our glacial environment, we scaled the dimensions of the seismic network and consequently of the whole glacier as 
well as the sampling rate of our data by a factor of 1000 . Seismic velocities and material properties are not affected by this scaling, so the ratio of wavelengths to spatial dimensions is preserved. A reflectivity code (Müller, 1985; Ungerer, 1990) served as a means to verify the results given by this scaled inversion because it allows for the generation of synthetic seismograms at glacier dimensions.

The study site of the present investigation was located in the ablation area and no firn or snow was present. In order to determine the seismic velocity structure, active seismic measurements were conducted (V. Gischig, unpublished manuscript, 2007) producing a velocity tomography based on arrival time inversions and waveform modeling. The results show that below the crevassing zone, the seismic velocities do not vary significantly with depth. The seismic velocities of the top $20 \mathrm{~m}$, however, can be significantly lower due to crevasses and fissures. Because the thickness of this slow layer is still smaller than the wavelengths at which the moment tensor inversions are performed, Green's functions are calculated for a half-space with $P$ and $S$ velocities of $3.63 \mathrm{~km} / \mathrm{sec}$ and $1.76 \mathrm{~km} / \mathrm{sec}$, respectively.

The influence of crevasses, fissures, and other inhomogeneities near the glacier surface also manifests itself in scattering and reflecting of seismic waves. The resulting complexity in the waveforms was reduced by using an acausal two-pole, two-pass Butterworth band-pass filter. As crevassing causes scattering and attenuation mainly near the surface, the seismograms of near-surface events were filtered between 5 and $30 \mathrm{~Hz}$, whereas those of intermediate events were filtered between 20 and $60 \mathrm{~Hz}$.

Moment Magnitude Scaling. Scalar moments were calculated in two different ways. In the case of the deviatoricmoment tensor inversion, the equation

$$
M_{0}=\frac{\left|m_{1}^{\prime}\right|+\left|m_{3}^{\prime}\right|}{2}
$$

was employed, where $M_{0}$ is the scalar moment and $m_{1}^{\prime}$ and $m_{3}^{\prime}$ are the largest and the smallest (in absolute magnitude) deviatoric eigenvalues of the moment tensor, respectively. For the moment tensors calculated via the full- and the crack + DC-moment tensor inversion schemes, the scalar moment was determined by

$$
M_{0}=\frac{\operatorname{trace}(\mathbf{M})}{3}+m_{1}^{\prime},
$$

where $\mathbf{M}$ is the full-moment tensor (Bowers and Hudson, 1999). Note that for a double-couple source both equations yield the same scalar moment.

Because of the artificial scaling of the sampling frequency and the source-receiver distances, the moment tensor inversion overestimates the scalar moment by a factor of $10^{6}$ (E) see Background Information of Moment Tensor Inversions in the electronic edition of BSSA).
Station Selection. As the instruments were placed directly on the glacier ice, surface melt required daily aligning and leveling of the seismometers. Even this did not guarantee correct alignment at all times. Therefore, the seismograms were scrutinized for quality before the inversion schemes were applied. One means to check for correct alignment was to ensure that the $P$ wave is primarily present on the radial component. Because a misalignment was usually a combination of rotation and tilt, it was not possible to reorient the sensor via a coordinate axes rotation about the vertical axis at the data processing stage. Furthermore, 2D or 3D scattering effects, that the 1D Green's function cannot account for, could result in $P$ energy on the transverse component. Therefore, the presence of significant $P$ signal on the transverse component was a criterion to exclude the seismogram from the inversion.

The zcor value determined in the inversion schemes is a further selection criterion. Clinton et al. (2006) have shown that the zcor value increases linearly with epicentral distance. Deviations of the zcor value from this linear relationship thus provide a good selection criterion for the set of stations to be used in a moment tensor inversion.

As a last check, the fit quality of each station was evaluated. If the fit of a seismogram was of extremely low quality compared to the other stations in the same inversion, it was removed. However, this was rarely the case. A possible bias may be introduced by differences in azimuthal coverage resulting from different sets of seismograms used in the inversions. This was important for the case of the intermediate cluster where the number of suitable stations was between 10 and 14 . Therefore, only the set of suitable stations common to all events was used in the individual inversions.

\section{Discussion of Inversion Results}

\section{Inversion of Explosion Signals}

In order to investigate the performance of the moment tensor inversion using a human source, we first present the results of the full-inversion scheme applied to two explosive charges set off at depths of 0.5 and $50 \mathrm{~m}$ in summer 2004. The former was placed into a small borehole, $0.5 \mathrm{~m}$ deep and about $5 \mathrm{~cm}$ in diameter. Subsequently, the borehole was filled with ice to the glacier surface. For the $50 \mathrm{~m}$ deep explosion, the charge was suspended in a water-filled borehole that had a diameter of about $30 \mathrm{~cm}$. The epicentral locations of both explosions are close to station G4A5 as shown in Figure 1. Figure 5 shows the resulting waveform fits for the unconstrained inversion. The signals of the 0.5 and $50 \mathrm{~m}$ deep explosions were band-pass filtered like the icequakes at shallow and intermediate depths, respectively. The overall variance reduction of the inversion of the shallow shot (Fig. 5a) is $80 \%$. At most stations the frequencies and amplitudes of the dominant phases are modeled well. The focal mechanism shows compressive first motions at all azimuths, which is expected for an isotropic source. This is also in agreement 
(a)

Tangential
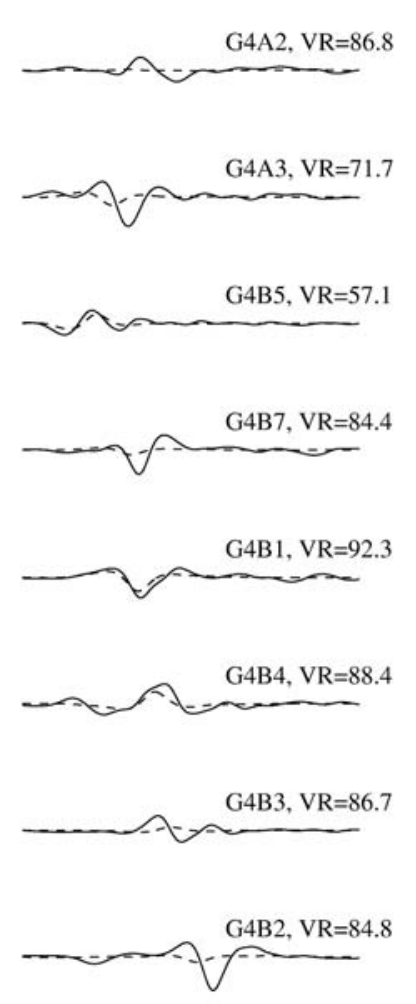

Radial
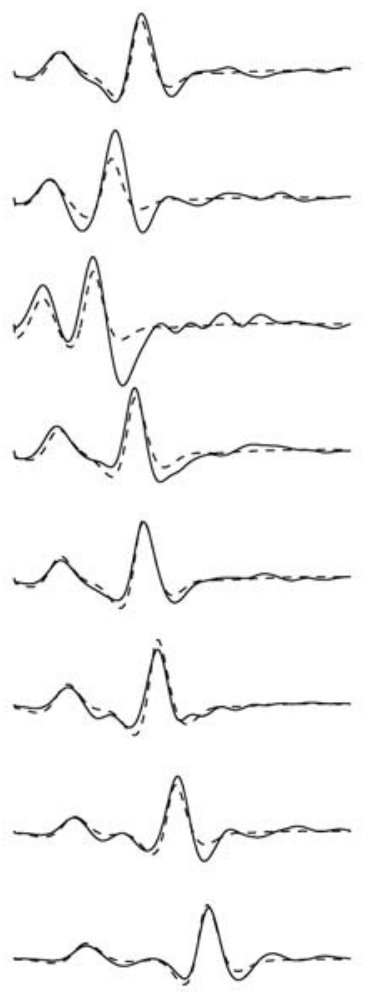

Vertical
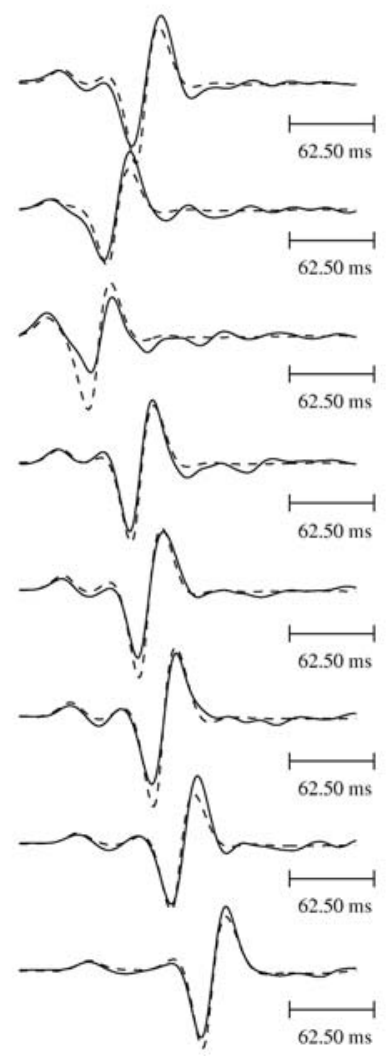

$\mathrm{Mw}=-0.49$

$\mathrm{Mo}=1.82 \mathrm{e}+08 \mathrm{Nm}$

$\mathrm{Mxx}=1.15 \mathrm{e}+08 \mathrm{Nm}$

Myy $=1.21 \mathrm{e}+08 \mathrm{Nm}$

$\mathrm{Mzz}=1.78 \mathrm{e}+08 \mathrm{Nm}$

Mxy $=-2.62 \mathrm{e}+06 \mathrm{Nm}$

$\mathrm{Mxz}=1.24 \mathrm{e}+07 \mathrm{Nm}$

$\mathrm{Myz}=9.62 \mathrm{e}+06 \mathrm{Nm}$

Strike $=118 ; 291 \mathrm{deg}$

Rake $=94 ; 84 \mathrm{deg}$

Dip $=58 ; 32 \mathrm{deg}$

Var. $\operatorname{Red}=7.99 \mathrm{e}+01$

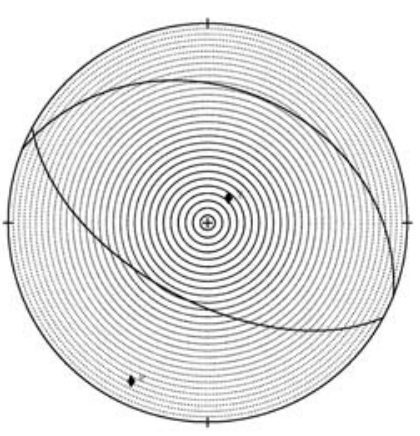

Figure 5. Waveform fits of explosions set off at depths of (a) $0.5 \mathrm{~m}$ and (b) $50 \mathrm{~m}$. The solid curves are for data, and the dashed curves are for synthetics. Epicentral locations are shown in Figure 1. Both fits were obtained using the full-moment tensor inversion scheme. As with icequakes, the signals of the shallow explosion lack the high frequencies found in the coda of the deeper explosion. Despite some signal on the tangential component, amplitudes and phases as well as frequencies are well modeled with a variance reduction of $80 \%$. The variance reduction of the deeper shot is substantially lower at 57\%. This reflects the considerable quantity of signal-generated noise observed on all components. In both cases, the plot of focal mechanism indicates a highly isotropic source as expected for explosions.

(Continued)

with the observed $P$ polarities. There is some signal on the tangential component that is not expected for a perfectly isotropic source. Some of it may be due to shear energy released in response to the explosion. However, because at some stations, such as G4B2, this wave phase is not modeled, it may be due to source effects that cannot be described by a firstorder moment tensor or due to complicated path effects.

The signals of the deep shot (Fig. 5b) contain higher frequencies than the shallow shot as discussed in the section titled Characteristics of Deep Icequakes. Although the dominant phases are again matched well, there is significant signal-generated noise on all components that cannot be reproduced by the synthetics. This causes a lower overall variance reduction of $57 \%$. The signal-generated noise may be due to waves traveling along the walls of the borehole. Furthermore, the presence of a strong phase on the tangential component of some stations, such as G4B4, hints toward the release of shear energy during the explosion, similar to the shallow explosion. The plot of focal mechanism again indicates a dominant isotropic moment tensor component.

It should be stressed that despite an approximately equal amount of explosive charge the moment magnitude of the shallow explosion is more than a magnitude larger than the deep explosion. Comparison with two other near-surface shots and two shots made at 100 and $150 \mathrm{~m}$ gave similar magnitude discrepancies. The magnitude difference therefore does not change with depth, but exists between shallow shots and deep borehole shots in general. We suggest two explanations for this observation: The first one we refer to as the free-surface effect, which arises when a seismic source is located at shallow depths compared to the wavelength used in the moment tensor inversion (Julian et al., 1998). In such cases, the normal tractions and their associated excitation coefficients vanish, and consequently only three moment tensor components can be determined. The isotropic part of the moment tensor as well as $M_{x z}$ and $M_{y z}$ cannot be resolved. Therefore, in the approximation of a symmetric first-order moment tensor, a horizontal tensile fault, for instance, located at such shallow depths does not radiate seismic waves. Ford et al. (2009) investigated this effect for regional moment tensor inversions of nuclear explosions using synthetic seismograms. Their results suggest that the free surface can contribute to the magnitude discrepancy between shallow and deep explosions; however, it is unlikely to explain the 
(b) Tangential
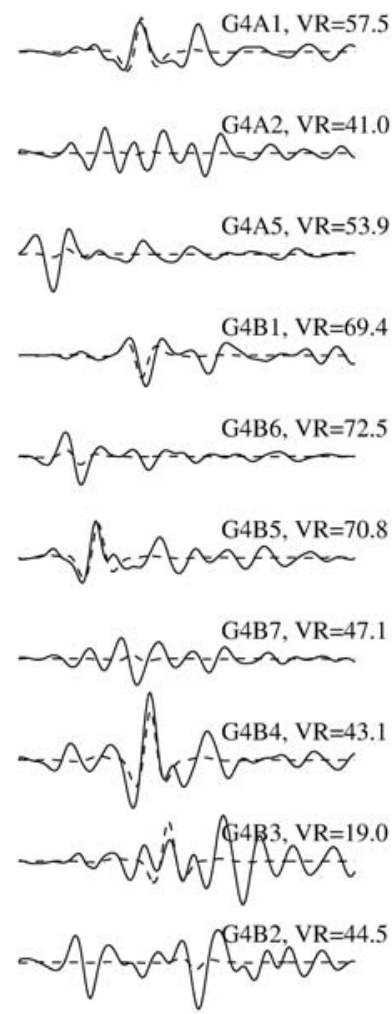

Radial

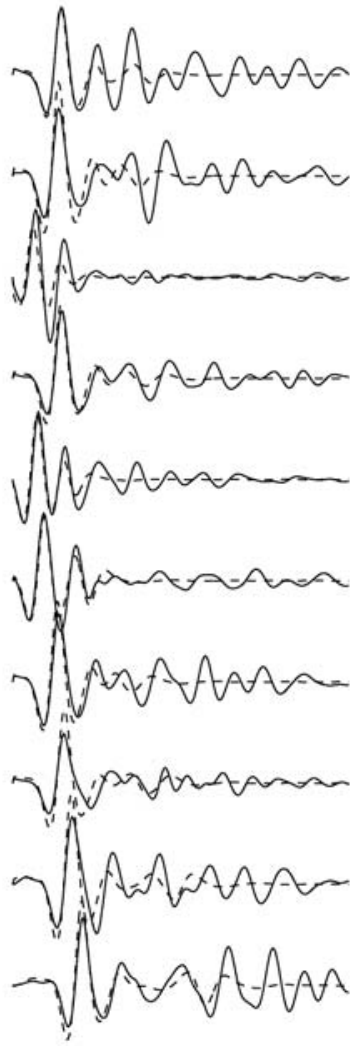

Vertical

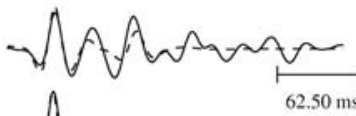

$\sqrt{2}$

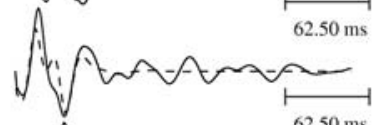

M

V.

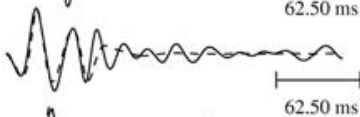

MnnffaAfa

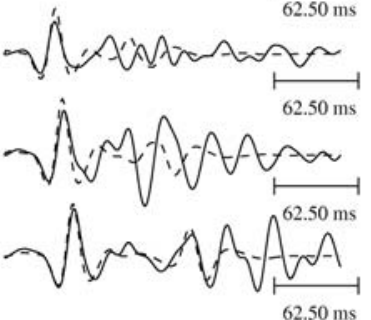

$\mathrm{Mw}=-1.63$

$\mathrm{Mo}=3.60 \mathrm{e}+06 \mathrm{Nm}$

$\mathrm{Mxx}=3.33 \mathrm{e}+06 \mathrm{Nm}$

Myy $=3.54 \mathrm{e}+06 \mathrm{Nm}$

$\mathrm{Mzz}=2.87 \mathrm{e}+06 \mathrm{Nm}$

$\mathrm{Mxy}=-1.30 \mathrm{e}+05 \mathrm{Nm}$

$\mathrm{Mxz}=-9.55 \mathrm{e}+04 \mathrm{Nm}$

$\mathrm{Myz}=-8.35 \mathrm{e}+04 \mathrm{Nm}$

Strike $=190 ; 40 \mathrm{deg}$

Rake $=-111 ;-67 \mathrm{deg}$

Dip $=50 ; 44 \mathrm{deg}$

Var. $\operatorname{Red}=5.71 \mathrm{e}+01$

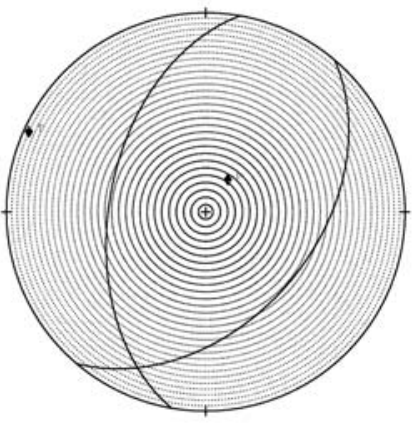

Figure 5. Continued.

difference of more than a magnitude. As a second reason for this magnitude difference we suggest differences in coupling of the explosion to the surrounding ice. The surface charges were placed into a much smaller hole $(5 \mathrm{~cm}$ diameter) than the deep borehole charges (30 $\mathrm{cm}$ diameter). Whereas the surface charges were covered with tightly packed ice debris, the borehole charges were hanging freely in the water-filled borehole. The coupling for the borehole explosions is likely much poorer, especially in the $z$ direction. The low value for $M_{z z}$ shown in Figure $5 \mathrm{~b}$ reflects this.

We stress that the magnitude differences observed for the shallow and deep borehole explosions may be partially due to free-surface effects. This has to be kept in mind when comparing inversion results of shallow and deep icequakes.

\section{Source Discrimination}

Following Hudson et al. (1989) we visualize the nature of the calculated moment tensors using source-type plots. These equal-area plots are a means to illustrate how strong the isotropic component is ( $k$ parameter, near-horizontal lines) and how much the deviatoric component differs from a pure double couple ( $T$ parameter, near-vertical lines). (E) More information on source-type plots is given in Background Information on Moment Tensor Inversions and Grid for Source-Type Plots after Hudson et al. (1989) in the electronic edition of BSSA.

Source-Type Plots for Explosions. Figure 6 shows the source-type plot of the full-moment tensor inversions of the explosions. Both moment tensors have high $k$ values meaning that they are dominated by the isotropic component. However, both solutions show some deviatoric component meaning that they are not pure explosions. This is likely an effect of shear stress released during the explosion; that can also explain some of the signal observed on the tangential components of the explosion seismograms (Fig. 5). At the same time this may also reflect some numerical instability that a full, unconstrained moment tensor is subject to. Keeping these observations in mind we will use source-type plots as approximate indicators of underlying source mechanisms.

Near-Surface Tensile Crack-Type Events. Table 1 gives a summary of the moment tensor inversion fit quality for all events considered. (E) The corresponding moment tensors are given in Table 1 in the electronic edition of BSSA. The full-moment tensor inversion usually exhibits the highest variance reduction because it allows the maximum number of degrees of freedom. 


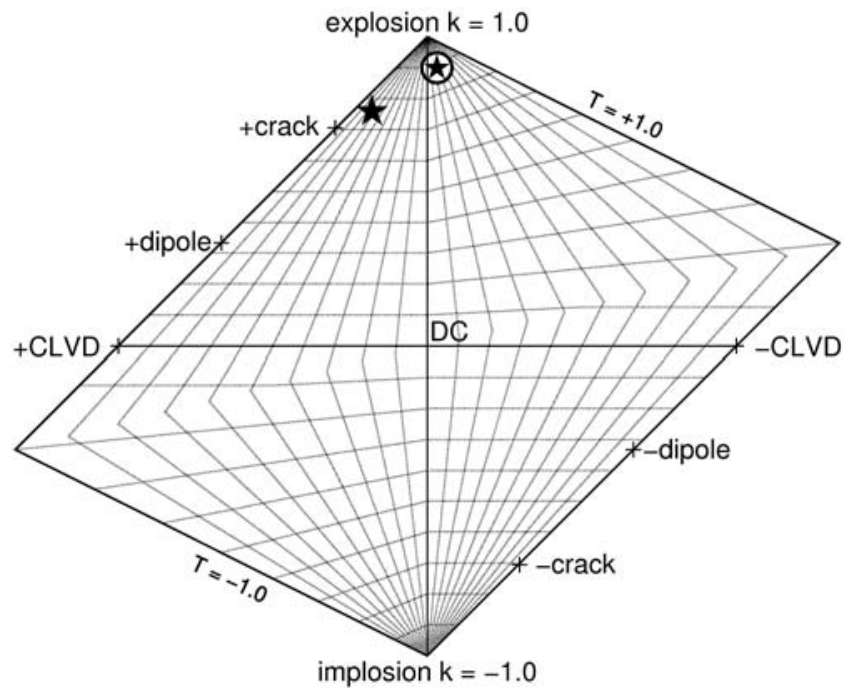

Figure 6. Source-type plot for moment tensors of the shallow explosion (star) and $50 \mathrm{~m}$ deep shot (circled star) as determined by the full-inversion scheme (Fig. 5). Both moment tensors show a large isotropic component (high- $k$ value) as expected for an explosion.

Figure 7 shows the waveform fits from the full-moment tensor inversion of a shallow icequake belonging to surface cluster A. With an average variance reduction of $74 \%$, amplitudes and frequencies of the measured seismograms are well reproduced by the synthetics. The plot of focal mechanism indicates compressive first $P$ motions as observed on all stations.

Figure $8 \mathrm{a}, \mathrm{d}$,g show the inversion results for surface cluster A. The full-moment tensor inversions indicate a dominating isotropic component (Fig. 8a). In this regime the parameter $T$ has little significance. Given the scatter of the

\section{Table 1}

Variance Reductions (in \%) of Moment Tensor Inversion Fits for the Events Discussed in This Article

\begin{tabular}{cccc}
\hline Event & Full $^{*}$ & Deviatoric $^{*}$ & Crack + DC $^{*}$ \\
\hline SURF_A 1 & 74 & 71 & 75 \\
SURF_A 2 & 63 & 58 & 62 \\
SURF_A 3 & 71 & 66 & 72 \\
SURF_A 4 & 65 & 57 & 65 \\
SURF_A 5 & 74 & 68 & 73 \\
SURF_B 1 & 74 & 74 & 73 \\
SURF_B 2 & 73 & 73 & 74 \\
SURF_B 3 & 72 & 71 & 67 \\
SURF_B 4 & 77 & 77 & 75 \\
SURF_B 5 & 74 & 74 & 72 \\
INT 1 & 64 & 36 & 62 \\
INT 2 & 69 & 44 & 68 \\
INT 3 & 65 & 50 & 67 \\
\hline
\end{tabular}

Small differences in station selection exist, but the band-pass filter of the events within a cluster is the same.

"Having the most degrees of freedom, the full-moment tensor inversion scheme usually exhibits the highest fit quality.

'For all intermediate events, the results of the deviatoricinversion scheme show significantly lower variance reductions than those of the full and the crack + DC schemes. results, no conclusion about the nature of the deviatoricmoment tensor component can be drawn. The deviatoric solutions (Fig. 8d) represent sources with mostly double couple and some negative CLVD component. In the case of the crack + DC inversion (Fig. 8g), all solutions are dominated by the positive tensile crack opening.

Table 1 shows the variance reductions of the waveform fits for surface cluster A. The fit quality of the full-moment tensor inversion is satisfactory at a variance reduction between about $65 \%$ and $75 \%$. The aforementioned plot of focal mechanism in Figure 7 indicates a highly isotropic moment tensor, which is consistent with the compressive $P$ motion observed at all seismometers. The deviatoric fit is slightly worse, with variance reductions decreasing by up to $8 \%$. The individual waveform fits show that the deviatoric fit does not reproduce the amplitude ratios of the $P$ to Rayleigh phase as well as does the full inversion. The variance reduction of the crack + DC inversion is closer to that of the full-moment tensor inversion than the deviatoric inversion. Using F-test statistics we evaluate the significance of the lower variance reductions calculated by the deviatoric inversion considering that it has five free parameters as opposed to the fullinversion scheme, which has six. The number of uncorrelated data points needed in the calculation of the F-test statistics is given by the low-pass filter corner (Templeton and Dreger, 2006). An improvement of fit quality for the more complex full-moment tensor model over the deviatoric model is significant if the F-test statistics indicate at least a 95\% confidence level. The results show that for all but one event the fit improvement of the full-moment tensor inversion over the deviatoric inversion is not significant.

Summarizing these findings, it can be stated that the crack + DC model with a dominating tensile crack component is the most likely model for the sources of surface cluster $\mathrm{A}$. This is in agreement with the compressive $P$ arrivals observed at all recording stations. The F-test statistics nevertheless show that for all but one event a deviatoric-moment tensor can model the data appropriately, too. This point will be commented further in the section titled Verification of Source Discrimination.

Near-Surface Double-Couple Events. Figure 9 shows an example of a waveform fit of a surface cluster B event obtained with the deviatoric-inversion scheme. The overall variance reduction is $77 \%$. The observed pattern of $P$-arrival polarity (Fig. 4) is consistent with the plot of focal mechanism.

The mechanisms given by the inversions of the events belonging to surface cluster B are shown in Figure 8b,e,h. The full-moment tensor solution again contains a considerable isotropic component. However, compared to the cluster A events, it is weaker and of opposite sign. With a less dominant isotropic component, the full-moment tensor inversion results indicate that the deviatoric source is more double couple than CLVD (Fig. 8b). Accordingly, the deviatoric solution places the source mechanisms close to the double-couple 
Tangential

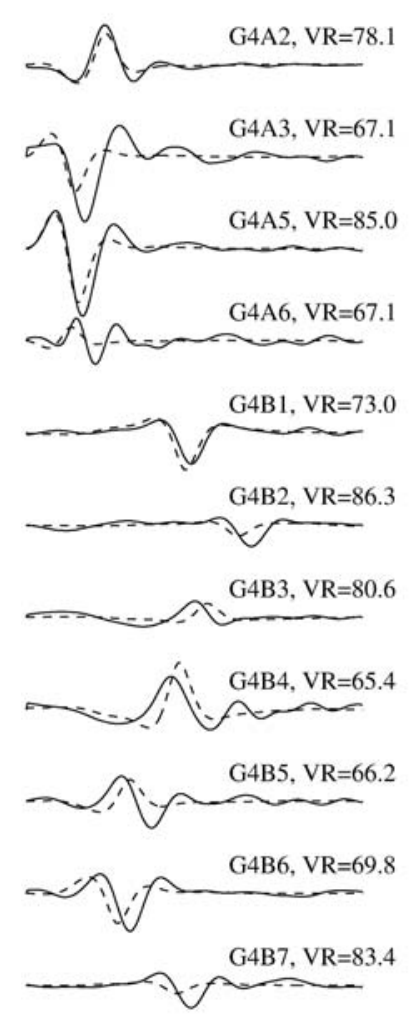

Radial
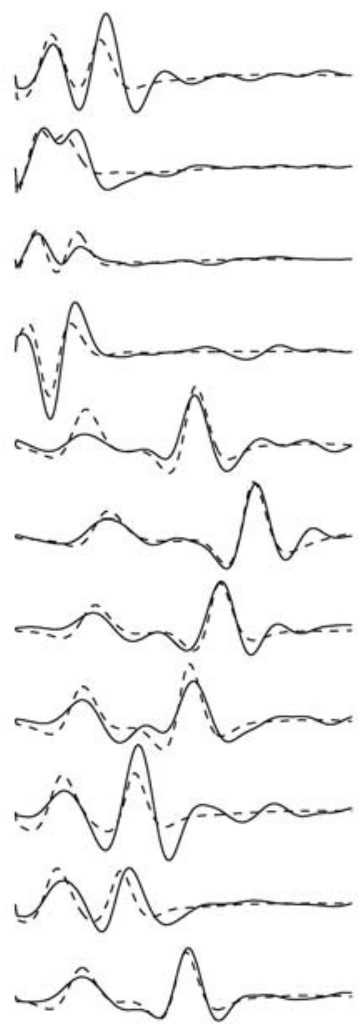

Vertical

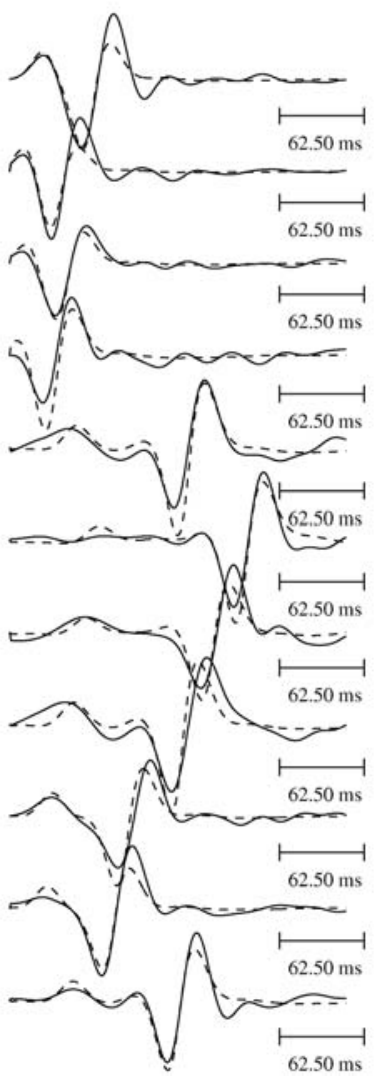

$\mathrm{Mw}=-1.56$

$\mathrm{Mo}=4.55 \mathrm{e}+06 \mathrm{Nm}$

$\mathrm{Mxx}=2.87 \mathrm{e}+06 \mathrm{Nm}$

Myy $=3.93 \mathrm{e}+06 \mathrm{Nm}$

$\mathrm{Mzz}=2.40 \mathrm{e}+06 \mathrm{Nm}$

$\mathrm{Mxy}=-7.48 \mathrm{e}+05 \mathrm{Nm}$

$\mathrm{Mxz}=1.54 \mathrm{e}+05 \mathrm{Nm}$

$\mathrm{Myz}=-7.23 \mathrm{e}+05 \mathrm{Nm}$

Strike $=187 ; 57 \mathrm{deg}$

Rake $=-115 ;-45$ deg

Dip $=67 ; 33 \mathrm{deg}$

Var. Red $=7.41 \mathrm{e}+01$

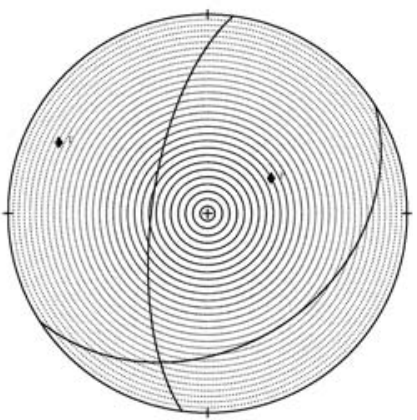

Figure 7. Waveform fits obtained with the full-moment tensor inversion of an event belonging to surface cluster A. The fitted time series (dashed curve) shows good agreement with the measured data (solid curve) giving an overall variance reduction of $74 \%$. The observed isotropic first-arrival pattern is consistent with the highly isotropic moment tensor (plot of focal mechanism).

region, with all but one event containing a small amount of CLVD (Fig. 8e). The crack + DC inversion recovers a moment tensor that is dominated by a double-couple source for all events (Fig. 8h) and possesses a small negative (closing) crack component. However, allowing such a negative isotropic component in the crack + DC inversion offers only an improvement in variance reduction of $1 \%$ or less compared to a pure double couple.

Table 1 shows that for this cluster the highest fit qualities are for the full-moment tensor inversion. This time, however, the deviatoric inversion shows comparable results as does the crack + DC model for all but one event. The F-test statistics show that no single model fits the data significantly better than the other two.

In the case of surface cluster B we observe that all inversion schemes achieve comparable fit quality. The differences in variance reduction are no more than $2 \%$ for all but one event. Both the full- and the deviatoric-moment tensor inversion schemes indicate a dominant double-couple component. The inverted crack + DC-moment tensor is dominated by the double-couple component (Fig. 8h) and improves the variance reduction by only $1 \%$ or less compared to a pure double couple. We therefore conclude that the events of surface cluster B have double-couple sources.
This is consistent with the distribution of the positive and negative polarities of first $P$ arrivals observed for these events (Fig. 4).

Intermediate Events. The source-types determined by the different inversion schemes applied to the events of the intermediate cluster are illustrated in Figure 8c,f,i. Similarly to the near-surface tensile crack-type events, the full-moment tensor inversions indicate a very large isotropic component (Fig. 8c). Unlike the other investigated clusters, the deviatoric solutions are mostly CLVD (Fig. 8f). The moment tensors calculated by the crack + DC inversion are all purely tensile crack (Fig. 8i).

As for the other clusters, the variance reductions of the full-moment tensor inversion are higher than those of the other schemes (Table 1). The variance reduction of the deviatoric inversion lies well below that of the full inversion, in one case by nearly $40 \%$. The fit quality of the crack + DC model is very close to that of the full-moment tensor inversion. In two cases the crack + DC model performs slightly worse, which compared to the results of the deviatoric inversion appears only marginal. The F-test statistics show that for all events the deviatoric inversion fits the data significantly worse. The differences in variance reductions between the 
Surface cluster A

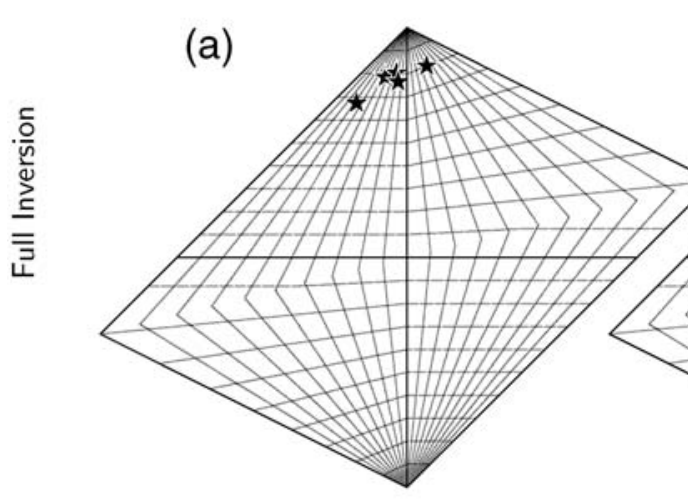

(d)
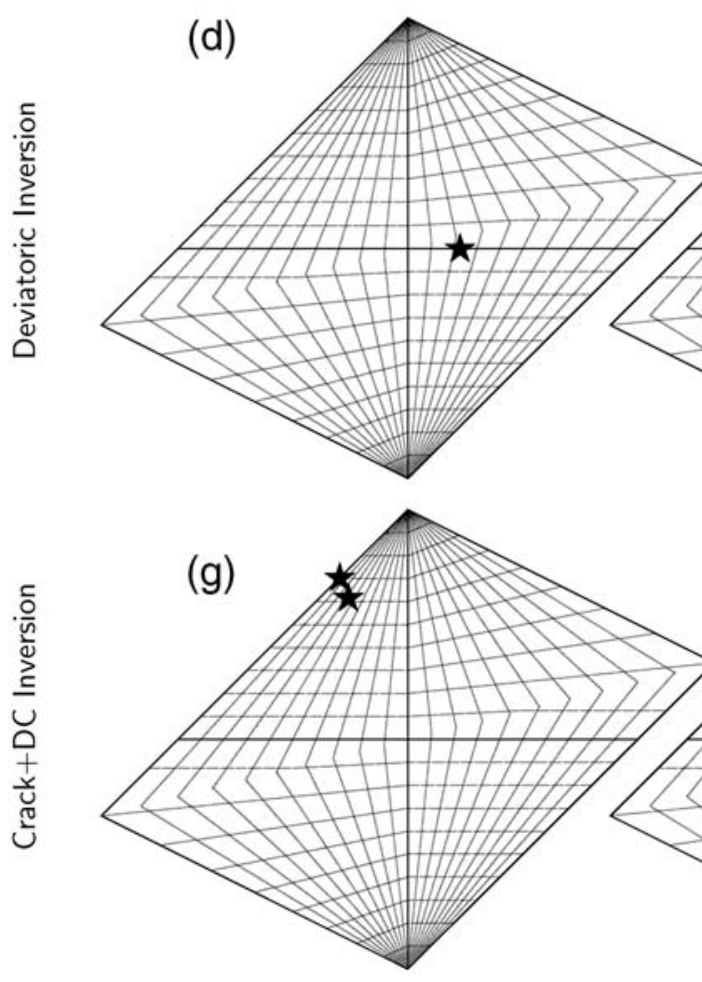

Surface cluster B

(b)

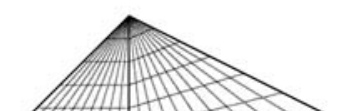

Intermediate Cluster

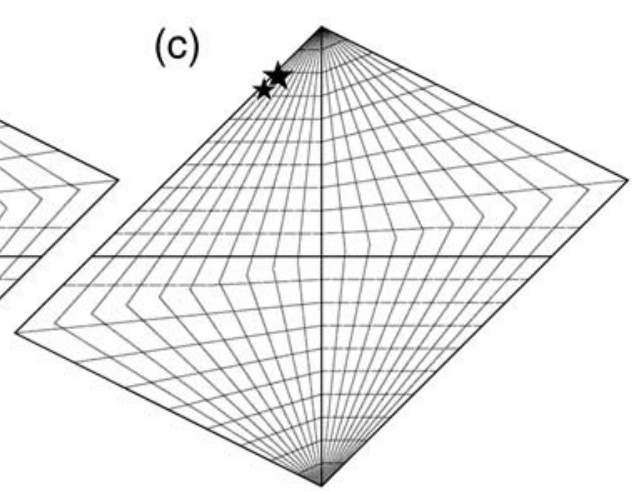

(c)

(e)
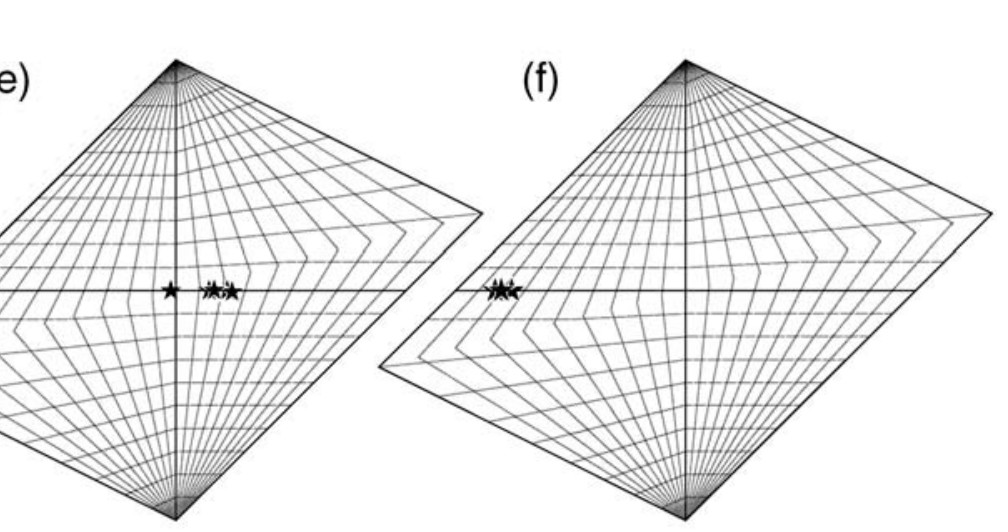

(h)
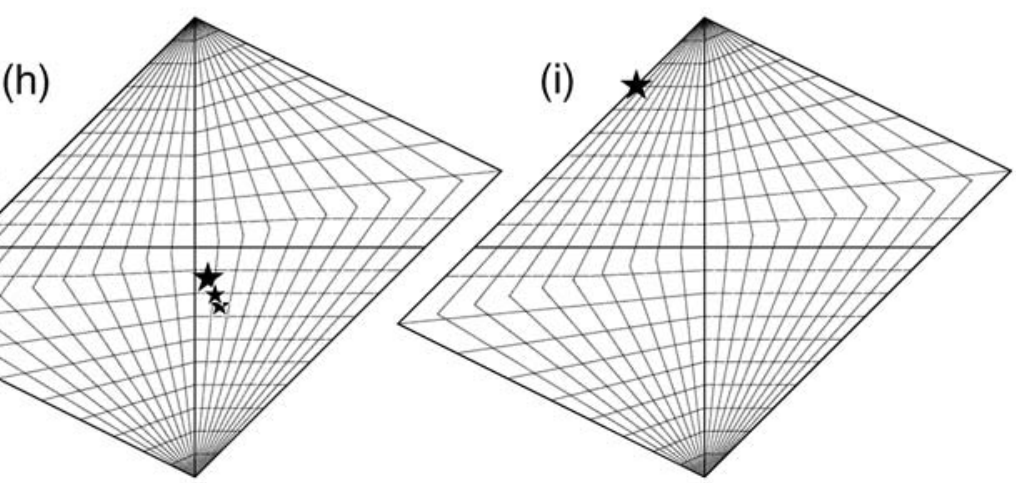

Figure 8. Source-type plots based on Hudson et al. (1989) for the three types of icequakes investigated. Stars indicate the location of the moment tensor solutions in $(k, T)$ parameter space. For illustration purposes, only one large star is plotted in cases where several solutions are very close together. Rows of the panels correspond to the different inversion schemes. Columns correspond to the different icequake clusters (surface cluster A, surface cluster B, and the intermediate cluster; see Figs. 1 and 3 for their locations). Note the large isotropic components determined by the full-moment tensor inversion of the icequakes of (a) surface cluster A and (c) the intermediate cluster. (g) and (i) In these cases the crack + DC inversion gave nearly a pure tensile crack moment tensor. (b) In the case of surface cluster B, the isotropic component given by the full-moment tensor inversion is much smaller and of opposite polarity compared to the other events. The (e) deviatoric and (h) crack + DC solutions are mostly double couple.

full and the crack + DC inversions, on the other hand, are not significant. Analysis of the waveform fits reveals the origin of the differences in variance reduction (Fig. 10). Unlike the crack + DC inversion, the deviatoric-constrained solution cannot model the impulsive $P$ phase on the radial and vertical components.

Summarizing these observations we conclude that the source type of the intermediate events is a tensile crack open- ing. Being dominated by an isotropic component, such a source cannot be modeled well by a deviatoric-moment tensor. This is the reason why the deviatoric-inversion scheme yields significantly lower variance reductions compared to the full and the crack + DC solutions. The compressive first $P$ arrivals observed at all seismometers are a further indication for a strong isotropic component and are thus in accordance with the proposed tensile crack model. 
Tangential
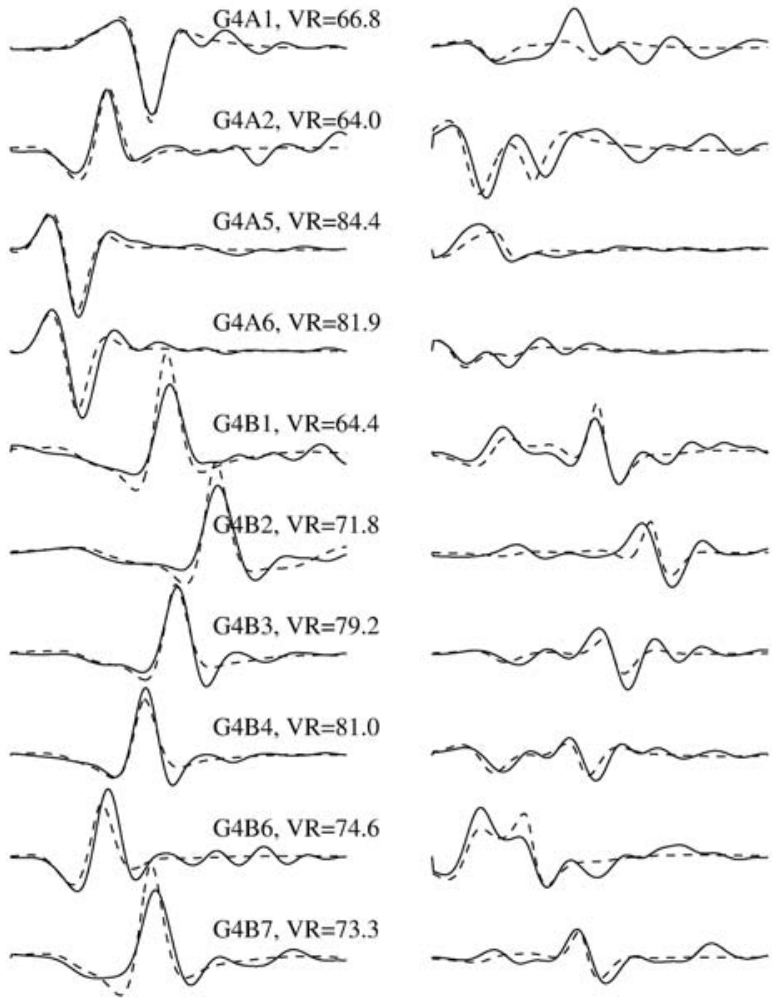

Vertical
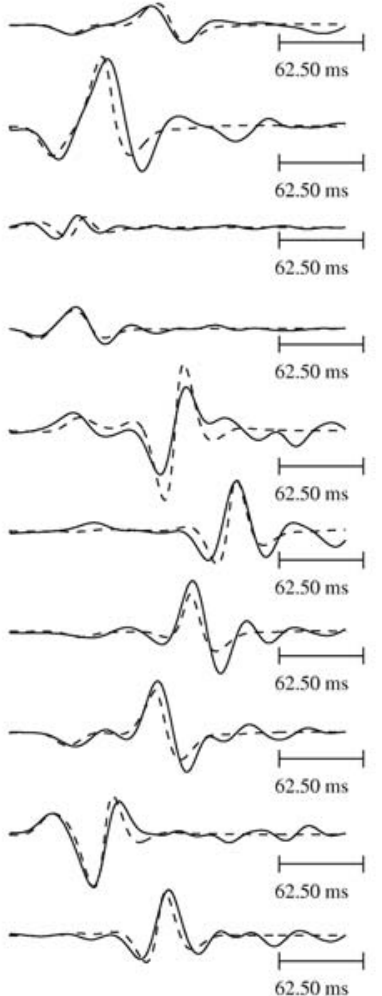

$\mathrm{Mw}=-1.62$

$\mathrm{Mo}=3.74 \mathrm{e}+06 \mathrm{Nm}$

$\mathrm{Mxx}=1.78 \mathrm{e}+06 \mathrm{Nm}$

Myy $=-3.07 \mathrm{e}+06 \mathrm{Nm}$

$\mathrm{Mzz}=1.29 \mathrm{e}+06 \mathrm{Nm}$

$\mathrm{Mxy}=-1.60 \mathrm{e}+06 \mathrm{Nm}$

$\mathrm{Mxz}=-1.56 \mathrm{e}+06 \mathrm{Nm}$

$\mathrm{Myz}=1.33 \mathrm{e}+06 \mathrm{Nm}$

Strike $=202 ; 305 \mathrm{deg}$

Rake $=143 ; 22 \mathrm{deg}$

Dip $=72 ; 55$ deg

Var. $\operatorname{Red}=7.66 \mathrm{e}+01$

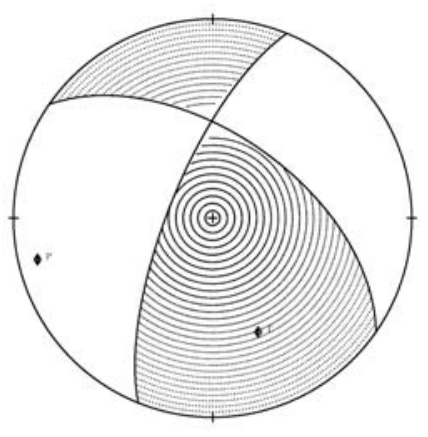

Figure 9. Waveform fits obtained with the deviatoric-moment tensor inversion of an event belonging to surface cluster B (solid curves for data and dashed curves for synthetics). The overall variance reduction is $77 \%$. The fault plane solution indicated by the plot of focal mechanism is consistent with the radiation pattern of first $P$ motions.

Verification of Source Discrimination. For the near-surface double-couple events (surface cluster B), the behavior of the variance reduction is in accordance with a double couple, which is the type of source suggested by information from source-type plots and waveform characteristics. All inversion schemes perform equally well. The reason is that a full-, a deviatoric-, and a crack + DC-moment tensor all include a double-couple component. Thus, it is not surprising that all inversion schemes are able to produce similarly highfit qualities for the case of a double-couple source.

For the cluster at an intermediate depth the variance reduction can be used as a good discriminator for the source model, which we suggest is a tensile crack opening. Compared to the deviatoric inversion, the crack + DC model had a fit quality nearly as good as the full-moment tensor inversion. Dominated by the CLVD component, the deviatoric inversion, however, gave variance reductions up to almost $40 \%$ lower than the full-moment tensor inversion. For tensile crack-type sources, this can be understood considering that the dominating isotropic source cannot be accounted for satisfactorily by a deviatoric model. This manifests itself in failure of the deviatoric fit to reproduce the dominant $P$-phase at all stations.
Despite these two cases, the solutions for the nearsurface crack-type events (surface cluster A) gave variance reductions that seemed somewhat inconsistent with the evidence provided by the source-type plots and the waveform characteristics: although we expect a tensile crack source we did not obtain a significant decrease in variance reduction when constraining the isotropic part of the moment tensor to be zero.

In order to further understand this issue we calculated synthetic seismograms for a pure tensile crack opening at $5 \mathrm{~m}$ and $100 \mathrm{~m}$ depth using an implementation of the reflectivity method (Müller, 1985; Ungerer, 1990). Because this numerical implementation differs from the FKRPROG software (Saikia, 1994) used to generate Green's functions, variance reductions of waveform fits of synthetic data generated with the reflectivity method may not reach $100 \%$. The synthetic seismograms were filtered with the same band-pass filters applied to the data. The stations were placed as if the source occurred near station A4, similar to the geometry of the two surface clusters (Fig. 1). We then inverted the seismograms using all three inversion schemes.

The inversions determined source types that are similar to those presented in Figure 8. The variance reductions for 
(a)

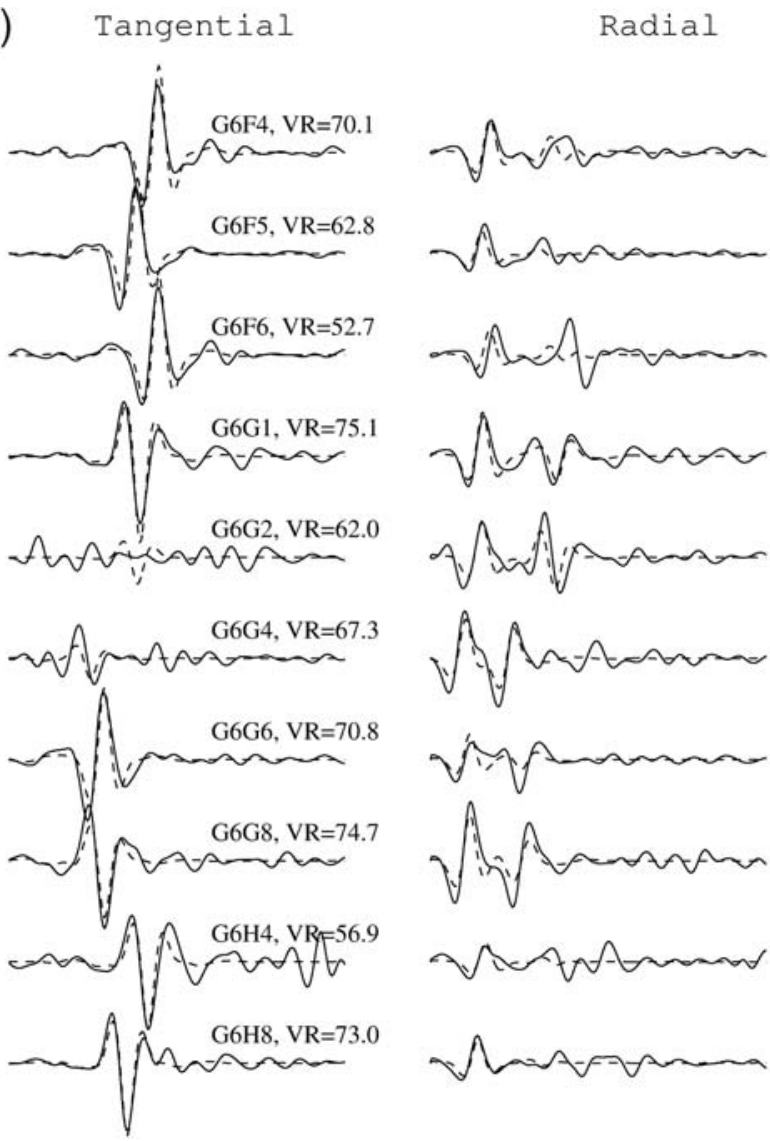

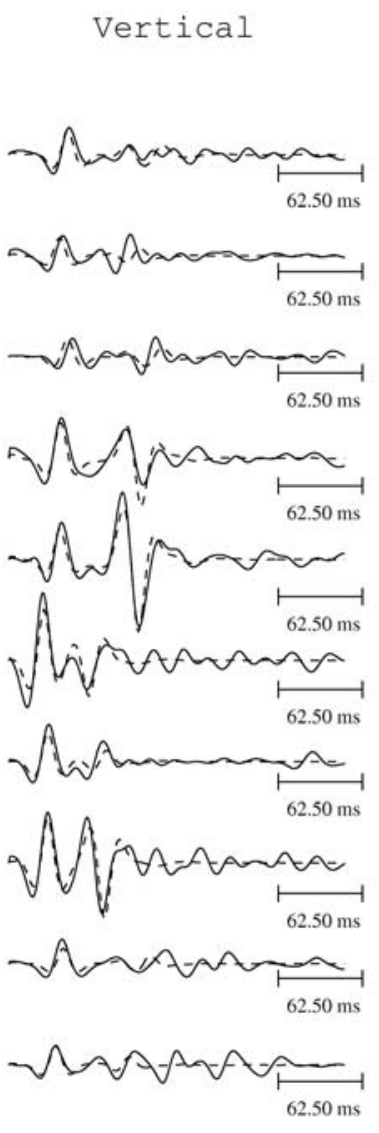

$$
\mathrm{Mo}=7.96 \mathrm{e}+05 \mathrm{Nm}
$$

$\mathrm{Mxx}=5.88 \mathrm{e}+05 \mathrm{Nm}$

Myy $=6.00 \mathrm{e}+05 \mathrm{Nm}$

$\mathrm{Mzz}=4.92 \mathrm{e}+05 \mathrm{Nm}$

Mxy $=-1.52 \mathrm{e}+05 \mathrm{Nm}$

$\mathrm{Mxz}=8.53 \mathrm{e}+04 \mathrm{Nm}$

$\mathrm{Myz}=-8.86 \mathrm{e}+04 \mathrm{Nm}$

Strike $=43 ; 43 \mathrm{deg}$

Rake $=-130 ;-130 \mathrm{deg}$

Dip $=67 ; 67 \mathrm{deg}$

Var. Red $=6.65 \mathrm{e}+01$

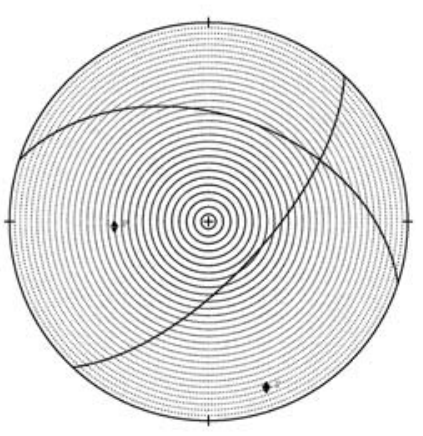

Figure 10. Waveform fits of an event belonging to the cluster at intermediate depth (solid curves for data and dashed curves for synthetics). (a) The fit using the crack + DC-inversion scheme and (b) using the deviatoric inversion. The fit quality of the latter is significantly lower (from $63 \%$ to $47 \%$ ) because the impulsive $P$ waves cannot be modeled by this inversion scheme. Note that the band-pass filter introduces acausal precursors to the $P$ arrival.

(Continued)

the shallow tensile crack were $89 \%$ (full inversion), $86 \%$ (deviatoric inversion), and $89 \%$ (crack + DC inversion). The respective values for the tensile crack synthetics at $100 \mathrm{~m}$ depth were $91 \%, 66 \%$, and $91 \%$. This is the same behavior that was observed for the real data: for the deviatoric fit of the tensile crack at $100 \mathrm{~m}$ the fit quality is much lower than that of the full and the crack + DC one. The deviatoric fit of the tensile crack source near the surface, on the other hand, produces variance reductions that are smaller by only a few percent. As in the case for the real data, the decrease in variance reduction for the deviatoric fit of the intermediate events is mainly due to the failure to fit the $P$-phase.

Thus, we conclude that the difference in behavior of the variance reductions for surface cluster $\mathrm{A}$ and the intermediate cluster is not caused by differences in source mechanisms. At least for the frequency window used in the present work, it appears to be inherent to the source depth in general: for deeper tensile cracks, no deviatoric-moment tensor can be found to satisfactorily model seismograms of a tensile crack opening, whereas for shallow events it is possible to some degree. This problem may not occur at other frequencies. However, the frequency content of signal and noise did not allow for moment tensor inversions at other frequency win- dows. It should be emphasized that for both the $5 \mathrm{~m}$ as well as the $100 \mathrm{~m}$ deep synthetic tensile crack the stations were placed in the same geometry around the epicenters. Therefore, the inversion results of the synthetic seismograms show that the equal ability of multiple models to fit the data is not an artifact of azimuthal coverage of recording stations.

Minson et al. (2007) were faced with a similar challenge discriminating source mechanisms for the 2000 Miyakejima volcanic earthquake swarm. Most of the sources were around $5 \mathrm{~km}$ deep. Considering the scaling relation applied in the present work, this depth corresponds to that of the surface clusters. Similar to the solutions of the surface cluster A events, the variance reductions of various models used to fit most Miyakejima waveforms showed only small differences for most events. Yet the authors argued for the crack + DC model because it constitutes a likely physical model for volcanic events, and it allowed forward modeling seismograms using inversion results of geodetic data. The first argument has considerable validity in the present work, as well: as a mechanism likely responsible for crevasse openings the tensile crack model represents the most plausible source for seismic signals in glacier ice. 
(b)

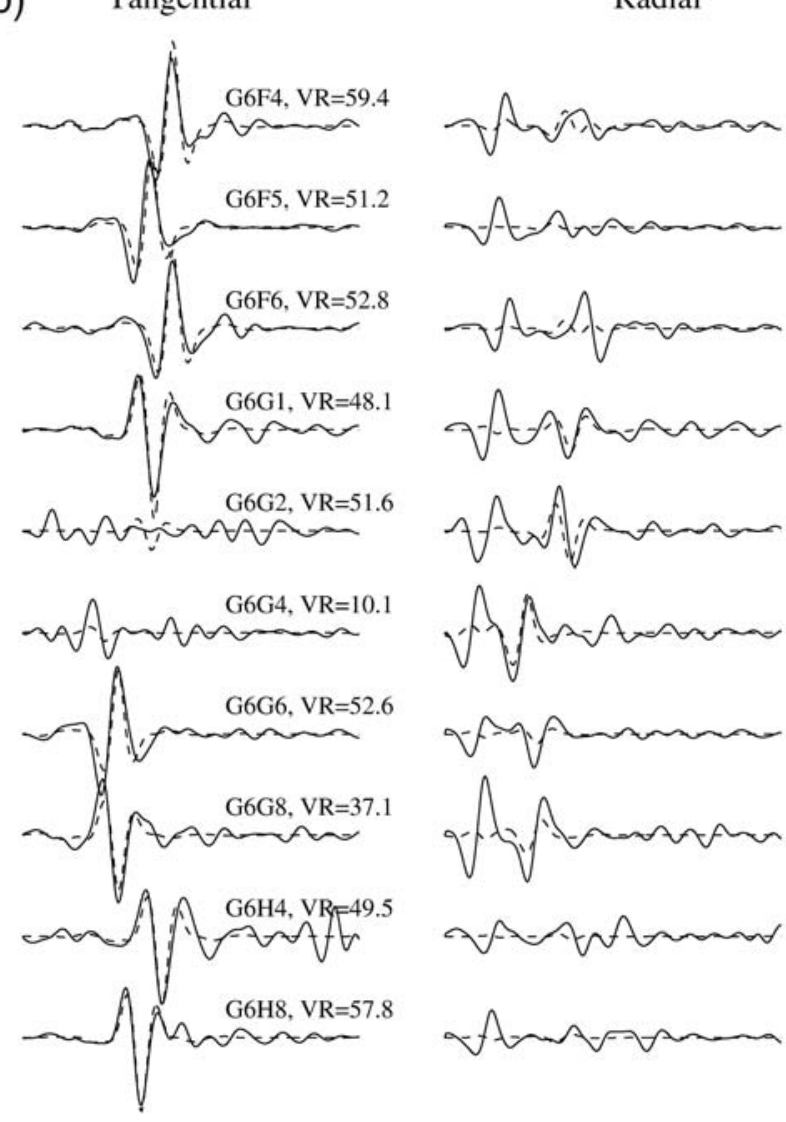

Vertical
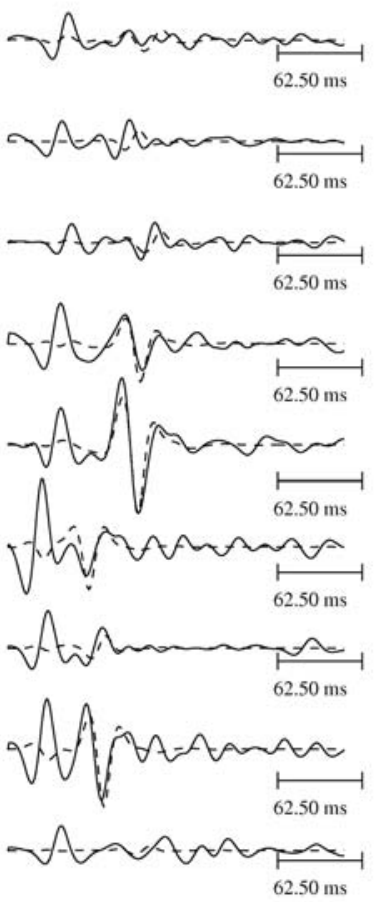

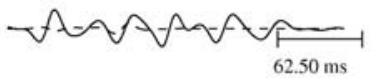

$\mathrm{Mw}=-2.42$

$\mathrm{Mo}=2.32 \mathrm{e}+05 \mathrm{Nm}$

$\mathrm{Mxx}=3.15 \mathrm{e}+04 \mathrm{Nm}$

Myy $=3.59 \mathrm{e}+04 \mathrm{Nm}$

$\mathrm{Mzz}=-6.75 \mathrm{e}+04 \mathrm{Nm}$

$\mathrm{Mxy}=-1.58 \mathrm{e}+05 \mathrm{Nm}$

$\mathrm{Mxz}=6.04 \mathrm{e}+04 \mathrm{Nm}$

$\mathrm{Myz}=-9.38 \mathrm{e}+04 \mathrm{Nm}$

Strike $=187 ; 91 \mathrm{deg}$

Rake $=-141 ;-10 \mathrm{deg}$

Dip $=82 ; 52 \mathrm{deg}$

Var. $\operatorname{Red}=5.01 \mathrm{e}+01$

Figure 10. Continued.

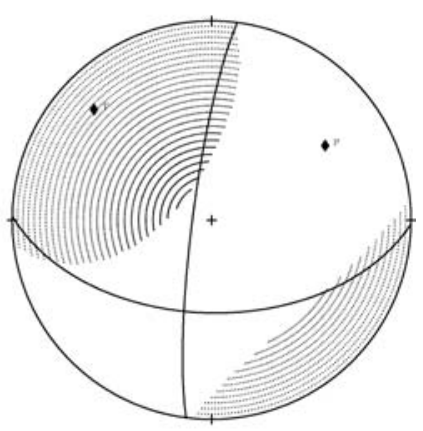

We furthermore used synthetic seismograms to evaluate the significance of the negative isotropic moment obtained for full and crack + DC inversions of the surface cluster B events (Fig. 8b,h). A double-couple source was placed at $5 \mathrm{~m}$ depth with the same station distribution that had been used for the previous calculations of synthetic seismograms. The fault plane orientation of the synthetic source was equal to the result of the crack + DC inversion of a surface cluster B event.

The full as well as the crack + DC inversion of the shallow double-couple synthetics both give a negative isotropic moment. The crack + DC inversion produces source-type parameters similar to those shown in Figure 8h. The full inversion determines a slightly positive $T$ value and a negative $k$ value whose magnitude is about one-third of the values given by the full inversions of the surface cluster B events (Fig. 8b). We conclude that the negative isotropic moment calculated by the full and crack + DC inversions of the surface cluster $B$ events is not significant because the inversions of synthetic seismograms of a pure double-couple source show this negative isotropic component, too. Furthermore, the crack + DC model with a negative isotropic moment provides an improvement in variance reduction of only $1 \%$ or less compared to a pure double couple. The negative isotropic moment is likely another manifestation of the effect

that the free surface has on the resolution of the isotropic component.

Interpretation of Mechanisms. Table 2 gives a summary of source parameters given by the moment tensors of the crack + DC inversion. Moment magnitudes were calculated using equations (2) and (3). Recall that for the events of surface cluster $\mathrm{A}$ and the intermediate cluster the tensile crack component strongly dominates the solution, whereas for those of surface cluster B the double-couple component is dominant. The rake values of the tensile crack-type events therefore carry little physical significance. Those of surface cluster $\mathrm{B}$ are around $150^{\circ}$. The strike values reflect orientations from the southwest to the northeast for all types of events. This is consistent with the local pattern of surface crevasses (see Fig. 1). The dip values range from near vertical to as low as $50^{\circ}$. Volumetric changes only occur for the tensile crack-type sources. According to Müller (2001) the volume of a tensile crack can be calculated from the isotropic moment $M_{\text {iso }}$ of a moment tensor via

$$
\Delta V=M_{\mathrm{iso}}(\lambda+2 \mu / 3),
$$

where $\lambda$ and $\mu$ are the Lamé parameters. The changes of the tensile crack volume calculated via equation (4) are on the 
Table 2

Fault Plane Orientations, Moment Magnitudes, and Volumetric Changes (in $\mathrm{cm}^{3}$ )

Calculated from the Moment Tensors Given by the Crack + DC Inversion

\begin{tabular}{ccrrrrc}
\hline Event & Mechanism & Strike $^{*}\left({ }^{\circ}\right)$ & Dip $^{*}\left({ }^{\circ}\right)$ & Rake $^{*}\left({ }^{\circ}\right)$ & \multicolumn{1}{c}{$\Delta V$} & $M_{\mathrm{w}}$ \\
\hline SURF_A 1 & crack & 40 & 50 & -60 & 320 & -1.6 \\
SURF_A 2 & crack & 198 & 80 & 108 & 110 & -1.9 \\
SURF_A 3 & crack & 202 & 78 & 105 & 400 & -1.6 \\
SURF_A 4 & crack & 215 & 85 & 50 & 140 & -1.8 \\
SURF_A 5 & crack & 36 & 86 & -28 & 290 & -1.6 \\
SURF_B 1 & DC & 208 & 68 & 156 & -77 & $-1.7(-1.6)$ \\
SURF_B 2 & DC & 208 & 73 & 152 & -100 & $-1.8(-1.6)$ \\
SURF_B 3 & DC & 200 & 70 & 156 & -26 & $-2.3(-2.1)$ \\
SURF_B 4 & DC & 202 & 72 & 144 & -77 & $-1.7(-1.6)$ \\
SURF_B 5 & DC & 202 & 67 & 150 & -90 & $-1.8(-1.7)$ \\
INT 1 & crack & 31 & 71 & -60 & 90 & -2.1 \\
INT 2 & crack & 35 & 69 & -95 & 110 & -2.1 \\
INT 3 & crack & 43 & 67 & -130 & 100 & -2.1 \\
\hline
\end{tabular}

Note that surface cluster $\mathrm{A}$ and the intermediate cluster represent almost entirely tensile crack events, whereas surface cluster B is double couple. Hence, the rake is of significance only for the surface cluster B sources. Volumetric changes were calculated via equation (4). Equation (2) was used to determine the moment magnitudes of the surface cluster B events. They are in good agreement with the moment magnitudes determined as in Boatwright (1980) (numbers in parentheses). The moment magnitudes for the remaining events were estimated using equation (3).

"Strike is measured clockwise from north.

order of $100 \mathrm{~cm}^{3}$ (Table 2). The sources of surface cluster A tend to undergo a larger volumetric change than the intermediate events. However, these differences in source parameters between shallow and deep events may at least partially be caused by effects of the free surface as discussed for the explosion inversions. The shear faulting of surface cluster B sources produces a negative volumetric change. Their absolute values are smaller than in the case of the surface cluster A events. As discussed in the section titled Verification of Source Discrimination, these volumetric changes are likely numerical artifacts of the inversion and do not have a physical meaning. The calculated moment magnitudes of all events lie within the range from -2.3 to -1.5 . (E) For the events of surface cluster B, the moment magnitudes are verified by the method given in Boatwright (1980) as explained in Background Information on Moment Tensor Inversions in the electronic edition of BSSA.

\section{Discussion}

Icequakes originating from near the glacier surface have been associated with crevasse openings since the work by Neave and Savage (1970) on the Athabasca Glacier in Alaska. We inverted a set of events with tensile crack-type mechanisms, which is consistent with the findings of the Athabasca study. Although we have only located less than a percent of the icequakes recorded in 2004 and 2006, the results of the waveform discriminator and our experience from looking at thousands of seismograms show that the tensile crack-type surface events (surface cluster A) are representative for well over $99 \%$ of the data set.
We also determined the source mechanisms of two different icequake types, which, according to their frequency of occurrence, can be considered somewhat atypical. The first set is also composed of surface events, but it differs from the typical crevassing events in that the sources are double couple rather than tensile cracklike. Aside from the implication that they are due to shear failure rather than tensile failure, the events are not associated with volumetric change. Table 2 shows that the shear-fault planes of the surface doublecouple events (surface cluster B) are very similar to the tensile fault planes of surface tensile crack-type events (surface cluster A). It has to be stressed that in this study we only concentrated on a few events out of the many thousands that have been detected each day. However, it is interesting to note that the shear-type events occur at the onset of the drainage of Gornersee. This observation suggests that shear failure is a response to the lake drainage, which is known to have the potential to significantly alter the glacier's flow direction (P. Riesen, unpublished manuscript, 2007; Sugiyama et al., 2007). In order to support this conjecture, a procedure to search the entire data set has to be developed.

The members of the intermediate cluster form another example of icequakes that cannot be attributed to the opening of surface crevasses. At these depths, it is reasonable to assume that in the absence of water that reduces the effective stress, the ice-overburden pressure inhibits tensile fracturing (Van der Veen, 1998). The tensile crack-type source mechanisms of the intermediate events therefore suggest that icequakes at these depths are related to hydrofracturing. This is consistent with observations of englacial fracturing made inside boreholes. Figure 11 shows an example of an englacial fracture intersecting a borehole drilled about $1200 \mathrm{~m}$ down 


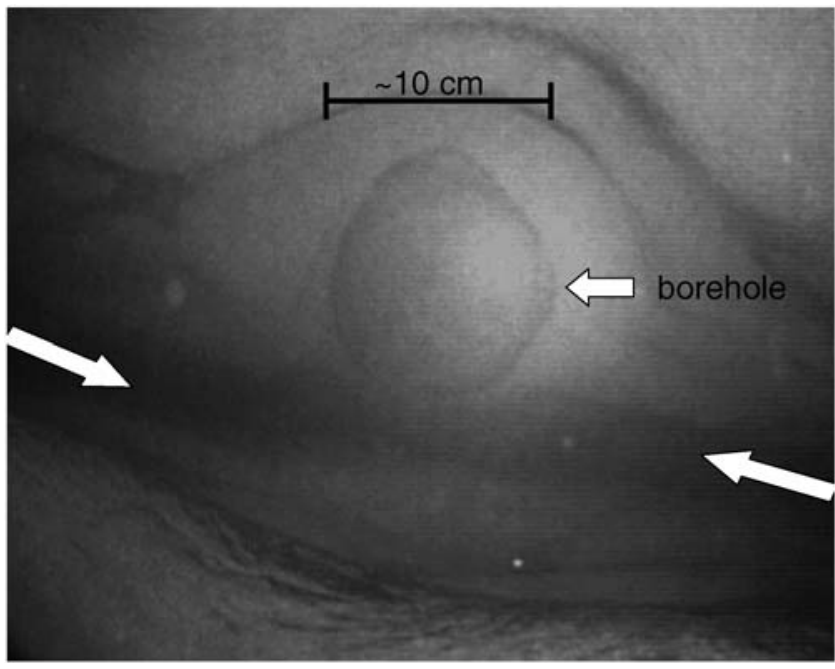

Figure 11. Picture taken inside a borehole at a depth of $270 \mathrm{~m}$ about $1200 \mathrm{~m}$ down glacier from the center of the seismic networks in 2004 and 2006. The glacier is over $300 \mathrm{~m}$ deep at this location. The picture shows clearly the intersection of the borehole with a crack (the two arrows at the side of the picture are along the strike of the crack), whose walls are on the order of a few centimeters apart. Openings of such cracks may be accompanied by the kind of intermediate-depth icequakes studied in the present work.

glacier of the seismic networks in 2005. Such fractures have also been observed in other studies (Harper and Humphrey, 1995; Fountain et al., 2005; Meierbachtol et al., 2006) and may have a significant influence on water flow inside temperate glaciers.

\section{Limitations of Inversion Schemes}

The most serious limitation of applying the Dreger (2003) approach is probably the 1D velocity model. This does not allow us to account for topographic details of the glacier. Although these are only on the order of a few percent of most of the source-receiver distances, the fit quality of the inversion is expected to suffer. The modeled travel times, for example, introduce small uncertainties, because the seismic stations do not lie exactly in a horizontal plane, as assumed by the applied velocity model. Of even greater concern is the topography of the glacier bed, which beneath the seismic arrays of 2004 and 2006 has an inclination of $30^{\circ}$ or more (Fig. 3). Therefore, the ice-bedrock interface cannot be described in a 1D velocity model. For this reason, the present study focuses only on the icequakes that occur at a distance from the glacier bed where bed reflections can be neglected.

Because the surface fractures inside the study site tend to align (Fig. 1), this can constitute an effective anisotropy of waveform attenuation as well as seismic velocities (V. Gischig, unpublished manuscript, 2007). As a consequence, seismic waves traveling perpendicular to the surface crevasses are slower and decay faster that those propagating parallel to the surface crevasses.
Moment tensor inversions of seismic sources near free surfaces are subject to numerical limitations independent of the numerical scheme used. If the sources are located at shallow depths with respect to the wavelength used in the inversion, the isotropic part of the moment tensor cannot be fully recovered (Dufumier and Rivera, 1997; Julian et al., 1998). In the present study this likely introduced errors in isotropic moments such as artificial negative volumetric changes for the double-couple sources of surface cluster B.

\section{Conclusion}

Using a simple scaling relationship and 1D Green's functions for a homogeneous half-space, we have successfully applied full as well as constrained moment tensor inversion schemes to seismograms from glacial icequakes recorded in dense campaign seismic networks on Gornergletscher, an alpine glacier in Switzerland. By interpreting the resultant moment tensors in terms of plausible physical models and scrutinizing the fit qualities of the inversions we arrived at the following central results: The sources for the vast majority of the several thousand icequakes measured each day are tensile crack openings near the glacier surface. Fault plane orientations indicate that these seismic events are associated with surface crevasses opening. The volumetric changes associated with these sources were calculated to be between 100 and $400 \mathrm{~cm}^{3}$. Shear-type events near the glacier surface do occur, although they occur much less frequently than tensile crack openings. The moment magnitudes of these events are between -2.0 and -1.5 . The existence of shear-type events indicates that icequakes near the glacier surface are not only produced by crevasse openings, as suggested by previous studies (Neave and Savage, 1970; Deichmann et al., 2000). Tensile crack-type seismic events also occur at intermediate depths within the glacier. Volumetric changes of these sources are about $70 \mathrm{~cm}^{3}$. At intermediate depths, the hydrostatic pressure inside the ice induced by the ice-overburden pressure is expected to be high enough to inhibit tensile fracturing. We therefore suggest that the intermediate events are related to the presence of water that reduces the effective stress to allow for tensile faulting.

In order to identify these distinct source types it is necessary to evaluate information from fit qualities, source-type plots, and waveform characteristics. Especially for the nearsurface events it is insufficient to consider solely the variance reduction of the waveform fits, because at the employed frequency range all three inversion schemes (full unconstrained, deviatoric only, and crack + DC) can be expected to, and do, achieve a satisfactory waveform fit of a tensile crack source. This underlines the difficulties inherent to source discrimination and the need to carefully consider which solution is physically most plausible. In the context of source discrimination it should be noted that source-type plots of full-moment tensor inversion results clearly separate double-couple events from tensile crack-type events because 
the latter have a large isotropic component (Fig. 8a,b,c). This is in good agreement with the findings of Ford et al. (2009).

In general it can be stated that the available data set was highly suitable for moment tensor inversions. The dense seismometer arrays provided a wealth of high-quality data. Furthermore, the high homogeneity of alpine glacier ice allows for the application of a simple velocity model to generate Green's functions. The procedure applied in this study can be very helpful in other studies of superficial or englacial fracturing provided the recording array is of sufficient quality and density to record broadband icequakes and accurately locate events. O'Neel and Pfeffer (2007) find that fracture processes inside tidewater glaciers may significantly weaken ice prior to glacier calving. Calculations of tensile crack opening volumes such as presented here will help understand the conditions under which a calving event will eventually occur. In Greenland, melt-water lakes can drain catastrophically through fractures, thus increasing the englacial seismic activity (Das et al., 2007). Accurate locations and source parameters may elucidate how the seismic activity is related to the water passage.

As previously mentioned, we have observed a small but significant number of basal icequakes with high confidence. In this article, we have not presented any moment tensors for these events. In the case of Gornergletscher, the geometry of the glacier bed (Huss et al., 2007; Fig. 1) requires that Green's functions for a 2D or 3D seismic velocity model have to be calculated. Despite this complication, the study of basal icequakes is highly valuable to a variety of glaciological aspects. These seismic signals can be related to stick-slip motion (Weaver and Malone, 1979; Roux et al., 2008; Wiens et al. [2008]), the failure across basal ice layers during the breaking off of hanging glaciers (Faillettaz et al., 2008), or changes in basal sliding due to changes in basal water pressures (Walter et al., 2008). Thus, icequakes occurring near the glacier bed should be a focus for future efforts of source parameter calculations.

\section{Data and Resources}

Seismograms used in this study were collected during the 2004 and 2006 Gornersee field campaigns. Access can be granted by the authors. Source-type plots were made with the Generic Mapping Tools (GMT) (Wessel and Smith, 1998).

\section{Acknowledgments}

We thank Thomas Forbriger for his assistance with the reflectivity code. The script to produce source-type plots with GMT was provided by Bruce Julian. Furthermore, we would like to express gratitude to Hansrudolf Maurer and Alan Green of the Applied and Environmental Geophyisics group at ETH for making recording equipment and borehole sensors available to this investigation. The quality of this manuscript was significantly improved by the reviews of Goran Ekström, Cezar Trifu, and an anonymous reviewer. This project was funded by the Swiss National Science Foundation, Grants Number 200021-103882/1 and 200020-111892/1.

\section{References}

Aki, K., and P. G. Richards (2002). Quantitative Seismology, Second Ed., University Science Books, Sausalito, California.

Anandakrishnan, S., and R. B. Alley (1994). Ice stream C, Antarctica, sticky spots detected by microearthquake monitoring, Ann. Glaciol. 20, 183-186.

Anandakrishnan, S., and R. B. Alley (1997a). Tidal forcing of basal seismicity of ice stream C, West Antarctica, observed far inland, J. Geophys. Res. 102, no. B7, 15,183-15,196.

Anandakrishnan, S., and R. B. Alley (1997b). Stagnation of ice stream C, West Antarctica by water piracy, Geophys. Res. Lett. 24, no. 3, 265-268.

Anandakrishnan, S., and C. R. Bentley (1993). Micro-earthquakes beneath ice streams $\mathrm{B}$ and $\mathrm{C}$, west Antarctica: observations and implications, J. Glaciol. 39, no. 133, 455-462.

Boatwright, J. (1980). A spectral theory for circular seismic sources; simple estimates of source dimension, dynamic stress drop, and radiated seismic energy, Bull. Seismol. Soc. Am. 68, 1117-1131.

Bowers, D., and J. A. Hudson (1999). Defining the scalar moment of a seismic source with a general moment tensor, Bull. Seismol. Soc. Am. 89, no. $5,1390-1394$.

Clinton, J. F., E. Hauksson, and K. Solanki (2006). An evaluation of the scsn moment tensor solutions: robustness of the $M_{\mathrm{w}}$ magnitude scale, style of faulting and automation of the method, Bull. Seismol. Soc. Am. 96, no. $5,1689-1705$.

Danesi, S., S. Bannister, and A. Morelli (2007). Repeating earthquakes from rupture of an asperity under an Antarctic outlet glacier, Earth Planet. Sci. Lett. 253, 151-158.

Das, S. B., I. Joughin, M. D. Behn, I. Howat, M. A. King, D. Lizarralde, and M. P. Bhatia (2007). Direct observations of melt-water lake drainage and the establishment of an efficient surface to basal water connection on the Greenland Ice Sheet, EOS Trans. AGU 88, no. 52 (Fall Meet. Suppl.).

Deichmann, N., J. Ansorge, F. Scherbaum, A. Aschwanden, F. Bernhardi, and G. H. Gudmundsson (2000). Evidence for deep icequakes in an Alpine glacier, Ann. Glaciol. 31, 85-90.

Dreger, D. S. (2003). TDMT_INV: time domain seismic moment tensor inversion, in International Handbook of Earthquake and Engineering Seismology, W. H. K. Lee, H. Kanamori, P. C. Jennings and C. Kisslinger (Editors), Vol. B, Academic Press, London, 1627 pp.

Dreger, D. S., and B. Woods (2002). Regional distance seismic moment tensors of nuclear explosions, Tectonophysics 356, no. 1-3, 122-125.

Dreger, D. S., H. Tkalcic, and M. Johnston (2000). Dilatational processes accompanying earthquakes in the long valley caldera, Science $\mathbf{2 8 8}$, no. $5463,122-125$.

Dufumier, H., and L. Rivera (1997). On the resolution of the isotropic component in moment tensor inversion, Geophys. J. Int. 131, no. 3, 595-606.

Ekström, G., M. Nettles, and G. Abers (2003). Glacial earthquakes, Science 302, no. 5645, 622-624.

Ekström, G., M. Nettles, and V. C. Tsai (2006). Seasonality and increasing frequency of Greenland glacial earthquakes, Science 311, 1756-1758.

Faillettaz, J., A. Pralong, M. Funk, and N. Deichmann (2008). Evidence of log-periodic oscillations and increasing icequake activity during the breaking-off of large ice masses, J. Glaciol. 54, no. 187, 725-737.

Ford, S. R., D. Dreger, and W. R. Walter (2009). Identifying isotropic events using a regional moment tensor inversion, J. Geophys. Res. 114, B01306, doi 10.1029/2008JB005743.

Fountain, A. G., R. B. Schlicting, R. W. Jacobel, and P. Jansson (2005). Fractures as main pathways of water flow in temperate glaciers, Nature 433, 618-621.

Harper, J. T., and N. F. Humphrey (1995). Borehole video analysis of a temperate glacier's englacial and subglacial structure: implications for glacier flow models, Geology 23, no. 10, 901-904.

Hudson, J. A., R. G. Pearce, and R. M. Rogers (1989). Source type plot for inversion of the moment tensor, J. Geophys. Res. 94, 765-774. 
Huss, M., A. Bauder, M. Werder, M. Funk, and R. Hock (2007). Glacierdammed lake outburst events of Gornersee, Switzerland, J. Glaciol. 53, no. 181, 189-200.

Jost, M. L., and R. B. Herrmann (1989). A student's guide to and review of moment tensors, Seism. Res. Lett. 60, no. 2: 37-57.

Joughin, I., I. Howat, R. B. Alley, G. Ekstrom, M. Fahnestock, T. Moon, Nettles, M., M. Truffer, and V. Tsai (2008). Ice-front variation and tidewater behavior on Helheim and Kangerdlugssuaq Glaciers, Greenland, J. Geophys. Res. 113, F01004, 11 pp.

Julian, B. R., A. D. Miller, and G. R. Foulger (1998). Non-double-couple earthquakes (theory), Rev. Geophys. 36, no. 4, 525-549.

Lee, W. H. K., and S. W. Steward (1981). Principles and application of microearthquake networks, in Advances in Geophysics, Supplement II, Academic, New York.

Meierbachtol, T. W., J. T. Harper, N. F. Humphrey, and J. Bradford (2006). Englacial and subglacial water flow elucidated by active and passive borehole experiments: Bench Glacier, Alaska (Abstract C31A-1229), EOS Trans. AGU, 87, no. 52 (Fall Meet. Suppl.), C31A-1229.

Menke, W. (1989). Geophysical Data Analysis: Discrete Inverse Theory, Academic Press, San Diego, California.

Métaxian, J.-P., M. M. Sebastián Araujo, and P. Lesage (2003). Seismicity related to the glacier of Cotopaxi Volcano, Ecuador, Geophys. Res. Lett. 30, no. 9, 36-1-36-4 doi 10.1029/2002GL016773.

Minson, S. E., and D. S. Dreger (2008). Stable inversions for complete moment tensors, Geophys. J. Int. 174, no. 2, 585-592.

Minson, S. E., D. S. Dreger, R. Bürgmann, H. Kanamori, and K. M. Larson (2007). Seismically and geodetically determined nondouble-couple source mechanisms from the 2000 Miyakejima volcanic earthquake swarm, J. Geophys. Res. 112, B10308, doi 10.1029/2006JB004847.

Müller, G. (1985). The reflectivity method: a tutorial, J. Geophys. Res. 58, 153-174.

Müller, G. (2001). Volume change of seismic sources from moment tensor, Bull. Seismol. Soc. Am. 91, 880-884.

Neave, K. G., and J. C. Savage (1970). Icequakes on the Athabasca glacier, J. Geophys. Res. 75, no. 8, 1351-1362.

O'Neel, S., and W. T. Pfeffer (2007). Source mechanisms for monochromatic icequakes produced during iceberg calving at Columbia Glacier, Alaska, Geophys. Res. Lett. 34, L22502, doi 10.1029/2007GL031370.

O'Neel, S., H. Marshall, D. McNamara, and W. T. Pfeffer (2007). Seismic detection and analysis of icequakes at Columbia Glacier, Alaska, J. Geophys. Res. 112, F03S23, doi 10.1029/2006JF000595.

Paterson, W. S. B. (1994). The Physics of Glaciers, Third Ed., Pergamon, New York.

Roux, P.-F., D. Marsan, J. P. Métaxian, G. O’Brien, and L. Moreau (2008). Microseismic activity within a serac zone in an alpine glacier (Glacier d'Argentière, Mont Blanc, France), J. Glaciol., 54, no. 184, 157-168.

Saikia, C. K. (1994). Modified frequency-wavenumber algorithm for regional seismograms using Filon's quadrature: modelling $\mathrm{Lg}$ waves in eastern North America, Geophys. J. Int. 118, no. 1, 142-158.

Smith, A. M. (2006). Microearthquakes and subglacial conditions, Geophys. Res. Lett. 33, no. 24.
Sugiyama, S., A. Bauder, P. Weiss, and M. Funk (2007). Reversal ice motion during the outburst of a glacier-dammed lake on Gornergletscher, Switzerland, J. Glaciol. 53, no. 181, 172-180.

Templeton, D. C., and D. S. Dreger (2006). Non-double-couple earthquakes in the long valley volcanic region, Bull. Seismol. Soc. Am. 96, no. 1, 69-79.

Tsai, V. C., and G. Ekström (2007). Analysis of glacial earthquakes, $J$. Geophys. Res. 112, F03S22.

Tsai, V. C., J. R. Rice, and M. Fahnestock (2008). Possible mechanisms for glacial earthquakes, J. Geophys. Res. 113, F03014.

Ungerer, J. (1990). Berechnung von Nahfeldseismogrammen mit der Reflektivitätsmethode, Diplom, Institut für Geophysik, Universität Stuttgart, Germany.

Van der Veen, C. J. (1998). Fracture mechanics approach to penetration of bottom crevasses on glaciers, Cold Reg. Sci. Tech. 27, no 3, 213-223.

Walter, F., N. Deichmann, and M. Funk (2008). Basal icequakes during changing subglacial water pressures beneath Gornergletscher, Switzerland, J. Glaciol. 54, no. 186, 511-521.

Weaver, C. S., and S. D. Malone (1979). Seismice evidence for discrete glacier motion at the rock-ice interface, J. Glaciol. 23, no. 89, 171-183.

Wessel, P., and W. H. F. Smith (1998). New, improved version of Generic Mapping Tools released, EOS 79, 579

Wiens, D. A., S. Anandakrishnan, J. P. Winberry, and M. A. King (2008). Simultaneous teleseismic and geodetic observations of the stick-slip motion of an Antarctic ice stream, Nature 453, 770-775.

Versuchsanstalt für Wasserbau, Hydrologie und Glaziologie (VAW)

ETH Zürich, 8092, Switzerland

walter@vaw.baug.ethz.ch

(F.W., M.F.)

Institut für Geopysik

ETH Hönggerberg, 8092, Switzerland

(J.F.C., N.D.)

Berkeley Seismological Laboratory

Berkeley, California 94720

(D.S.D.)

Department of Geological and Planetary Sciences

California Institute of Technology

Pasadena, California 91125

(S.E.M.)

Manuscript received 29 May 2008 